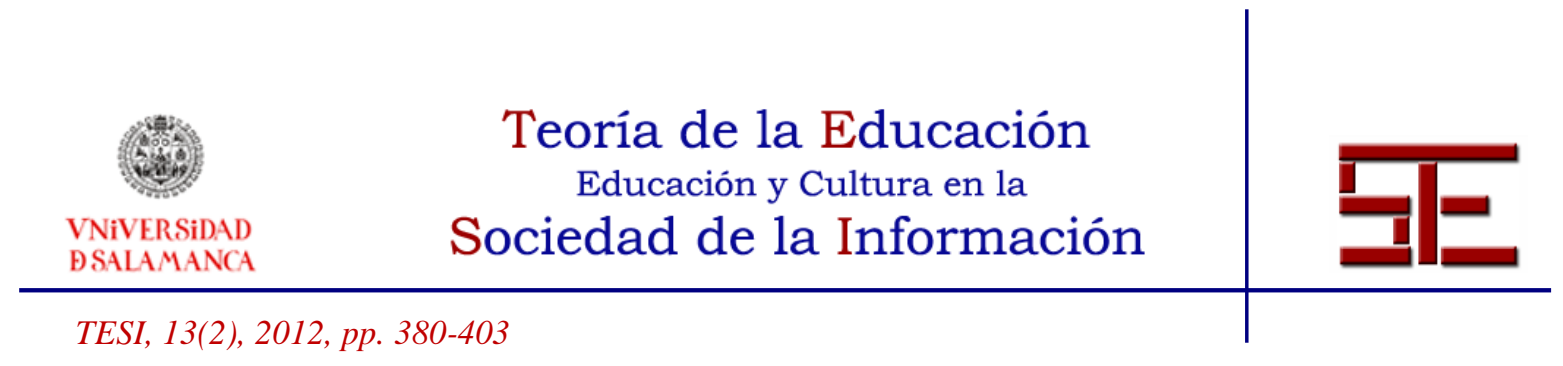

\title{
LA PARTICIPACIÓN INFANTIL: CONCEPTO DIMENSIONAL EN PRO DE LA AUTONOMÍA CIUDADANA
}

Resumen: La participación infantil representa, en la actualidad, un elemento clave en el entorno de la ciudadanía y de la educación. Se sustenta en unas sólidas bases legislativas que la reconocen, la defienden y la impulsan. Pero, es imprescindible que deje de ser un discurso para ser una realidad que forme parte de la cotidianidad donde la infancia alcance la máxima del ejercicio autónomo de la ciudadanía. Para alcanzar esta máxima, es necesario ampliar el concepto de participación infantil y reconocer toda su complejidad. Si se identifican las dimensiones que lo retroalimentan y dan sentido a la sistematización de la práctica responsable y autónoma de la ciudadanía. La finalidad de esta comunicación es profundizar en las principales dimensiones del concepto de la participación infantil que refuerzan su significado y su concreción en la cotidianidad incidiendo en la promoción e impulso de la autonomía ciudadana. Para ello se analiza el concepto de participación integrando sus múltiples dimensiones: como valor democrático, contenido formativo, metodología de trabajo, experiencia educativa, principio que impulsa el desarrollo, responsabilidad ciudadana, ejercicio político, representación de la infancia, y por último como emoción y pasión.

Palabras clave: participación infantil; ciudadanía; responsabilidad; autonomía ciudadana; valor democrático; ejercicio político.

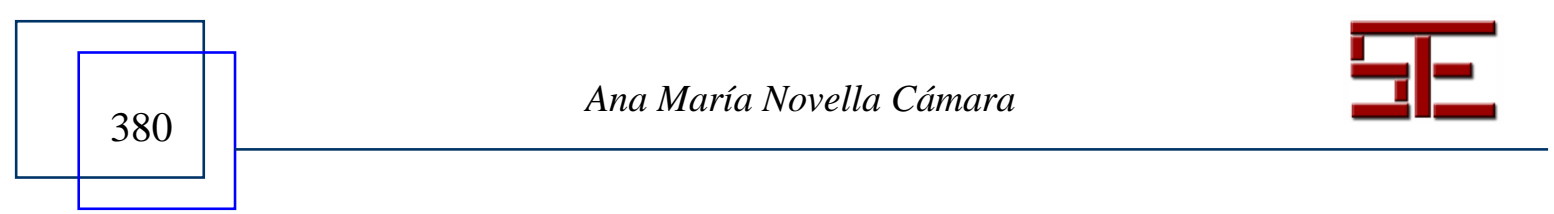




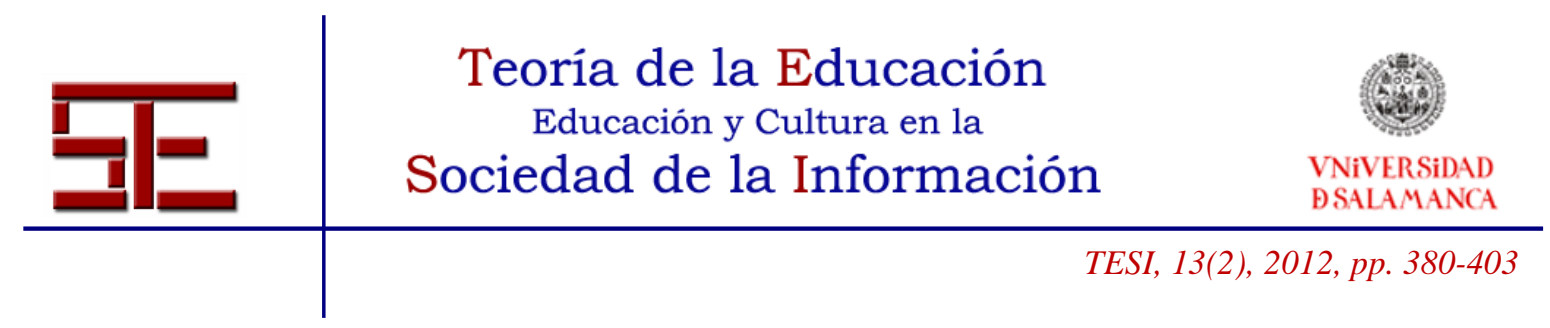

\title{
CHILD PARTICIPATION: DIMENSIONAL CONCEPT IN PRO AUTONOMY CITIZEN
}

\begin{abstract}
Child participation is, at present, a key element in the environment of citizenship and education. It is based in solid legislative bases that recognize child participation, defend it, and promote it. But, it is imperative to turn from rhetoric into a reality that is part of everyday life where children reach the maximum self-governing exercise of their citizenship. To achieve this maximum, we must expand the concept of child participation and to recognize its complexity, by identifying the dimensions that feed each other and give meaning to the systematization of the responsible and autonomous practice of citizenship. The purpose of this paper is to analyze the main dimensions of the concept of child participation that reinforce their meaning and its concretization in everyday life, emphasizing the promotion and improvement of autonomous citizenship. To achieve this, we analyze the concept of participation by integrating its multiple dimensions: as a democratic value, educational content, methodology of work, educational experience, developmental principle, civic responsibility, political exercise, representing children, and finally as emotion and passion.
\end{abstract}

Keywords: child participation; citizenship; responsibility; autonomy citizen; democratic values; political exercise.

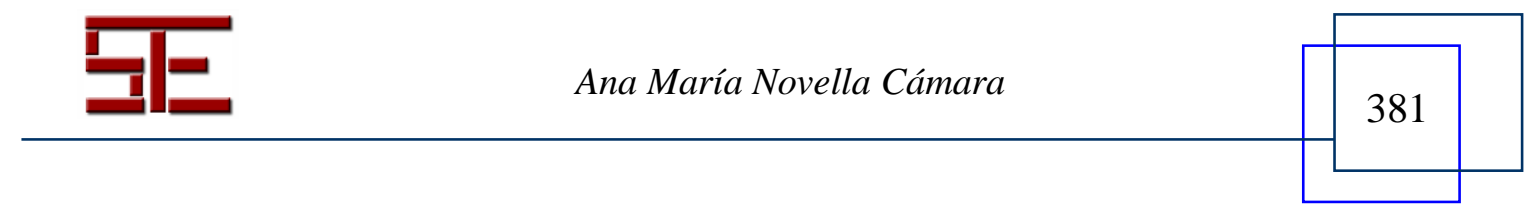




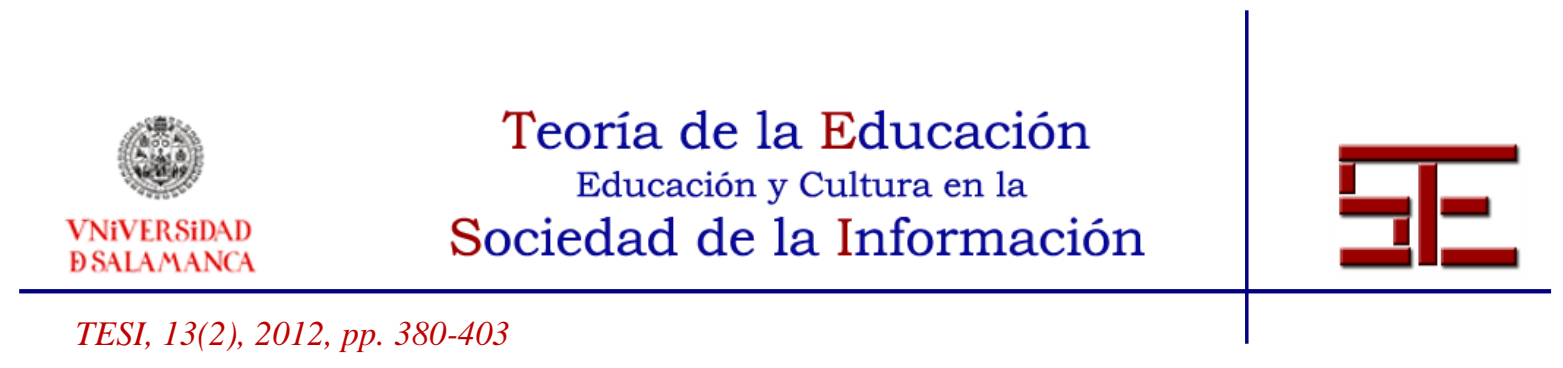

\title{
LA PARTICIPACIÓN INFANTIL: CONCEPTO DIMENSIONAL EN PRO DE LA AUTONOMÍA CIUDADANA
}

\author{
Fecha de recepción: 20/09/2011; fecha de aceptación: 20/10/2011; fecha de publicación: 26/07/2012
}

\author{
Ana María Novella Cámara \\ anovella@ub.edu \\ Universidad de Barcelona
}

\section{INTRODUCCIÓN}

Hablar de participación implica adentrarse en un terreno pantanoso, ya que su significado da pie a múltiples lecturas e interpretaciones. Además, se ha de tener en cuenta que en la última década ha sido uno de los conceptos más sobreutilizados y desvirtuados, que se puede explicar desde diferentes miradas, desde diferentes posiciones e, incluso, desde intereses contrapuestos o, como mínimo, ambivalentes. Compartimos la idea de que la participación se ha acabado convirtiendo en algo que todo el mundo invoca, porque nadie puede declararse contrario, pero para cada cual tiene un contenido y significado diferentes (Fernández Enguita, 1992).

La participación es "tomar parte en algo". Todos y todas estaremos de acuerdo en esta definición aparentemente tan simple. Pero resulta que estamos delante de uno de los conceptos más complejos y de carácter multidimensional de las ciencias de la educación. Concepto al que se han acercado desde la sociología, antropología, las ciencias políticas, la psicología y las ciencias de la educación.

La complejidad se incrementa cuando nos adentramos al concepto de participación infantil. En la actualidad la participación infantil está en su mejor momento, porque tiene unas buenas bases legislativas que la reconocen, la defienden y la impulsan. Se ha convertido en un estandarte, en una marca de calidad, en un contenido político, en una forma de trabajar... Pero todo esto es una apariencia y no es suficiente, porque se mueve en la esfera de los buenos propósitos y de los discursos políticamente correctos. La participación infantil está en boca de todos y todas, pero falta la parte más esencial y es que sea real, que forme parte de nuestra cotidianidad y sobre todo que pensemos en ella como formativa de la identidad de los niños. Que no sea sólo una actividad extra, puntual, excepcional, sino que esté integrada en el sí de las relaciones que mantienen los niños y sea una forma de estar y de construir la sociedad y su identidad. Por esto último, todavía nos queda mucho camino por recorrer, aunque tengamos las bases para hacerlo nos falta aquello más esencial que es la disposición a hacerla real y posible.

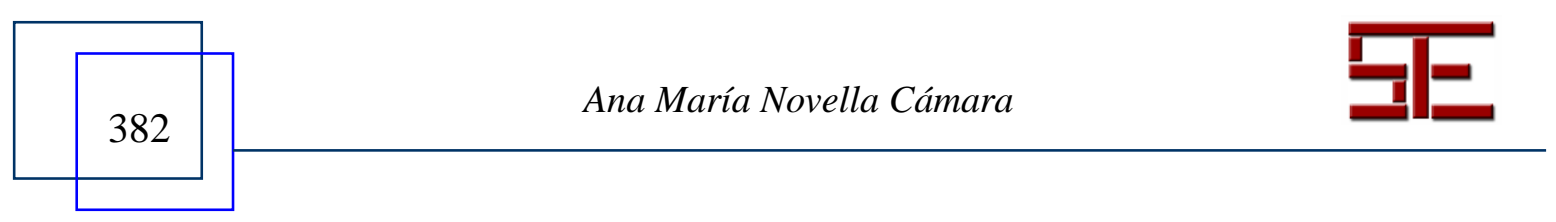




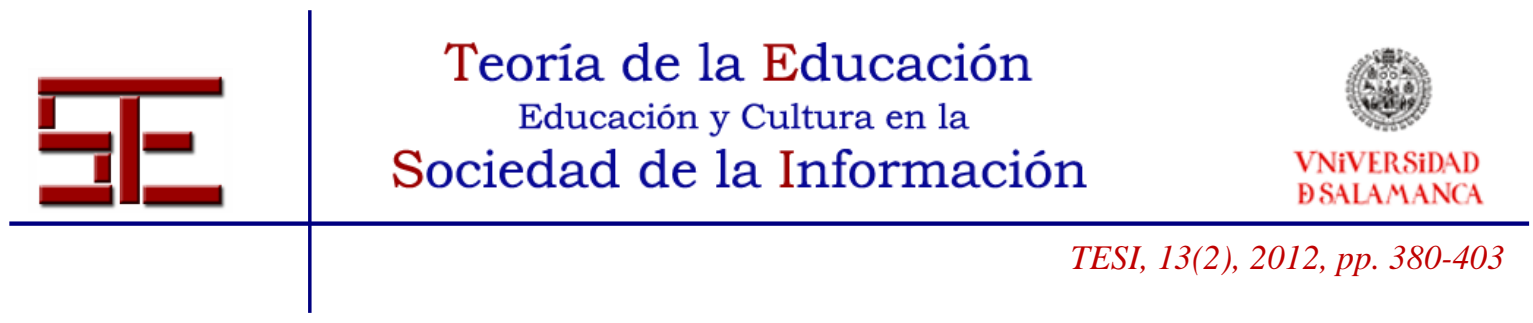

Desgraciadamente, los niños y las niñas continúan siendo invisibles para la participación y el ejercicio autónomo de este derecho. Transformar esta situación es todo un reto.

La invisibilidad participativa es una cuestión que nos ha de ocupar y preocupar a todos y a todas. Todos somos responsables de que los niños tomen parte activa en los asuntos que los afectan. Todos somos responsables de que nuestro día a día este impregnado de la participación infantil. Pero, ¿cuando hablamos de participación infantil de qué estamos hablando?

La finalidad de esta comunicación es adentrarse en esta cuestión, aproximarse a las dimensiones conceptuales de la participación infantil que rodean el ejercicio autónomo de la ciudadanía. El marco teórico que se presenta se caracteriza por ser dinámico y evolutivo, puesto que está en permanente construcción y reconstrucción por parte de cada uno de los agentes educativos que se aproximan a él. Proviene de una formación básica fundamentada en teóricos de referencia dentro de las Ciencias Sociales y, en especial, de la Pedagogía.

\section{2.- LA PARTICIPACIÓN, ALGO MÁS QUE UN DERECHO}

En la mayoría de las ocasiones, cuando hablamos de participación infantil lo hacemos desde la vertiente del derecho. Alzamos la voz para revindicar su defensa y cumplimiento.

La Convención de los derechos del niño (20 de noviembre de 1989) es el primer documento dónde queda reconocido el derecho de los niños a participar en todo aquello que les afecta. Este texto vinculante, con fuerza jurídica obligatoria, recoge intereses y necesidades civiles protegidos. Y lo hace desde tres vertientes: la primera es el reconocimiento del derecho a expresar su opinión y que ésta sea tenida en cuenta; la segunda es la importancia de capacitar a los niños para reivindicar el cumplimiento de los artículos de la Convención; y la tercera es la asunción de responsabilidades que supone el ejercicio de los derechos.

En los organismos internacionales a favor de los derechos de los niños se considera que la Convención instauró el principio conocido por las "3Ps": Protección, Provisión y Participación. Desde una perspectiva de la calidad de vida, Casas (1998) añadió dos Ps más: Prevención y Promoción.

La participación como derecho ha necesitado de su promoción activa ante las resistencias y oídos sordos del mundo adulto. Acercarnos a la participación únicamente

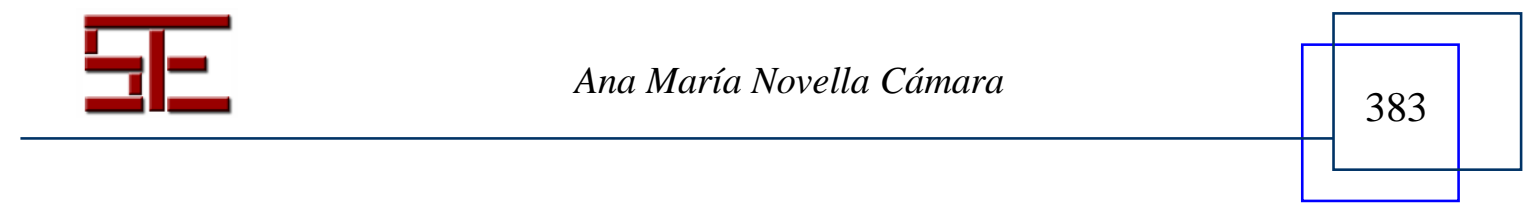




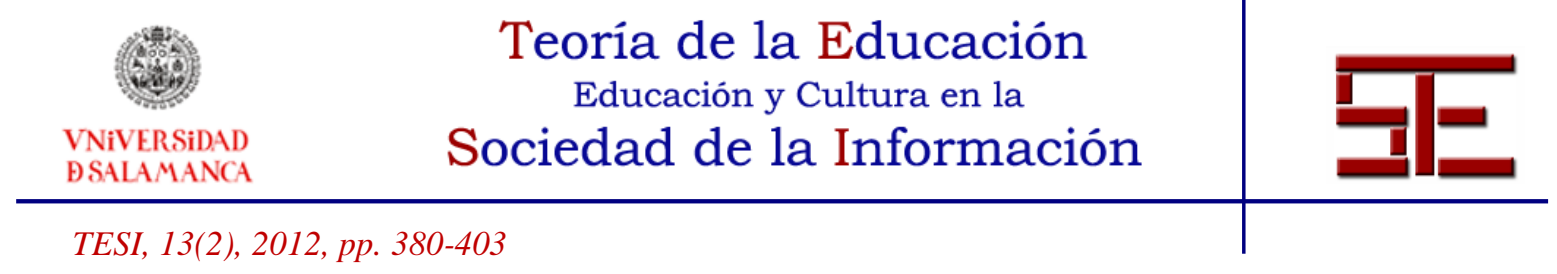

como derecho es un planteamiento reduccionista, aunque es una opción que no se debe despreciar pues es realmente imprescindible. La participación infantil, desde esta perspectiva del derecho, ha sido estandarte de grandes organismos y organizaciones que revindican a nivel mundial este cambio de reconocimiento de los derechos civiles de la infancia. Estas reivindicaciones globales se sitúan en la esfera de lo intangible desde las que es difícil identificar el agente responsable de su operativación. Una de las primeras transformaciones que se han de lograr es reducir esta distancia y nombrar un agente activo próximo que operativice los derechos civiles de los niños. La Convención en sus artículos proactivos (art. 42 al 45) responsabiliza a los Estados a promover los derechos y a articular mecanismos de supervisión. El Estado es un agente concreto que entre sus políticas está responsabilizarse de la infancia, aunque sigue siendo un ente demasiado lejano y distante a la ciudadanía. La participación requiere de proximidad, por ello debe ser un tema central en las políticas municipales. Las ciudades son los agentes, que, junto la unidad suprema del Estado, han de articular la participación infantil desde acciones locales específicas y prácticas locales.

La ciudad debe generar una dinámica educadora que incorpore los ciudadanos en el diseño del proyecto social que la orienta y la define. Hace falta incorporar el ciudadano no sólo para garantizar que todas las voces están representadas dentro del proyecto y que, por lo tanto, nadie se sienta excluido, sino para garantizar la formación de una ciudadanía cada vez más protagonista y competente en la construcción del proyecto de ciudad. Este proceso también supone una ciudad que forme para la ciudadanía y que le permita ejercer su derecho a tomar parte en las decisiones públicas. En este caso, estaríamos ante uno de los mejores indicadores de calidad de la ciudad. "La calidad de la ciudad se mide por el grado del ejercicio de la ciudadanía: los ciudadanos hacen la ciudad y la ciudad hace los ciudadanos" (Trilla, 1998, 19).

En definitiva, estamos reivindicando que la ciudad desarrolle al máximo su función educativa para garantizar la construcción de una ciudad y de una ciudadanía autónoma consciente de su responsabilidad dentro del proyecto colectivo e individual. Pero, no es suficiente con tomar conciencia; es conveniente facilitar el ejercicio de estas responsabilidades y motivarlas. Entre la ciudadanía, hay un cierto desconocimiento, desinterés, desaliento y una cierta desconfianza respecto los mecanismos y procesos participativos. De alguna forma, "hemos abdicado del ejercicio de la ciudadanía" (Araujo, 1999, 46) y, si estamos de acuerdo con la idea de que la ciudad "es aquello que los ciudadanos queremos que sea", debemos buscar en la función educativa de la ciudad cómo motivar y favorecer el resurgimiento de la implicación en su construcción. Sobre todo hemos de preocuparnos de cómo acompañamos a los niños y a las niñas en

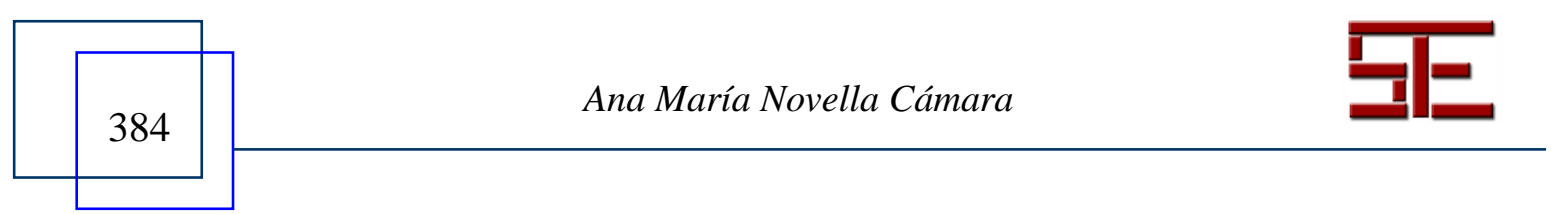




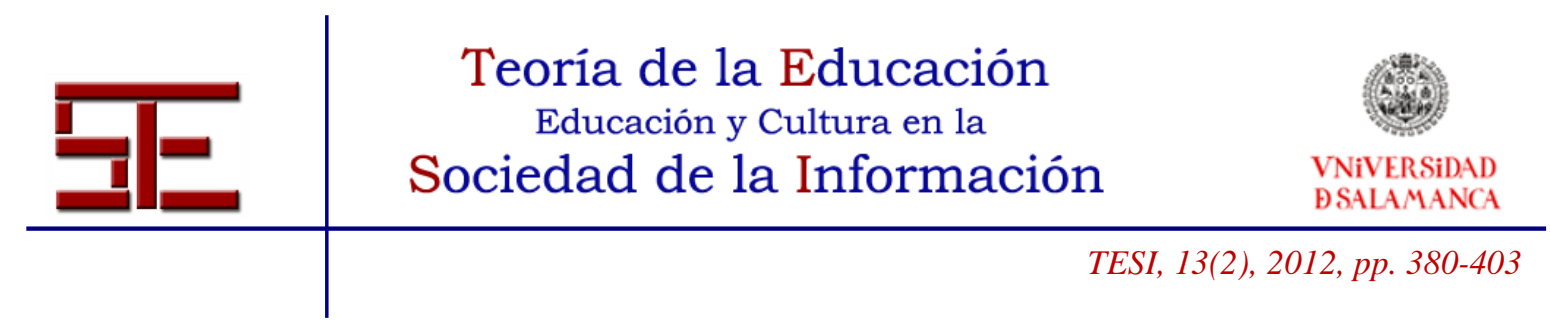

alcanzar su autonomía, su construcción de su ciudadanía activa y comprometida. Por este motivo, algunos de los principales interrogantes que se plantean los agentes sociales son: ¿qué ciudad? y ¿qué educación? En el marco del Congreso Internacional de Ciudades Educadoras de Génova (2004), la Diputación de Barcelona presentó una ponencia, en colaboración con Subirats, que traía por título: “¿Qué educación para qué ciudades?". En esta ponencia se defienden unos rasgos característicos de la ciudad, los responsables de los cuales son tanto los ciudadanos como los organismos públicos. Según Subirats, la relación entre estos dos agentes se sustenta en dos principios básicos, que son: la corresponsabilidad colectiva y la participación ciudadana.

Algunas ciudades ya han avanzado hacia este camino, son las llamadas ciudades educadoras. Éstas ya han recogido, en diferentes movimientos y documentos, las orientaciones para que sea posible la participación a partir del compromiso y la activación de diferentes estrategias políticas y educativas para toda la ciudadanía, incluida la infancia. A continuación, se muestran dos de los artículos de la Carta de las Ciudades Educadoras, firmada en el VIII Congreso Internacional de Ciudades Educadoras (Génova, 2004), que manifiesta este compromiso.

9. La ciudad educadora fomentará la participación ciudadana desde una perspectiva crítica y corresponsable. Para ello, el gobierno local facilitará la información necesaria y promoverá, desde la transversalidad, orientaciones y actividades de formación en valores éticos y cívicos.

Estimulará, al mismo tiempo, la participación ciudadana en el proyecto colectivo a partir de las instituciones y organizaciones civiles y sociales, tomando en consideración las iniciativas privadas y otras formas de participación espontánea.

20. La ciudad educadora deberá ofrecer a todos sus habitantes, como objetivo crecientemente necesario para la comunidad, formación en valores y prácticas de ciudadanía democrática: el respeto, la tolerancia, la participación, la responsabilidad y el interés por lo público, por sus programas, sus bienes y sus servicios.

La ciudadanía supone una determinada percepción de la ciudad, la aprehensión de nuevos valores culturales y democráticos; un sentimiento de identificación, una conciencia de pertenencia; un ejercicio de la participación, del compromiso y de la solidaridad: la ciudad se sitúa en el campo de la educación y de los valores para el impulso de la formación de la autonomía y responsabilidad de sus ciudadanos. Compartimos con Joan Subirats (2004) la idea de que la educación, se ha de entender como una responsabilidad colectiva y como un instrumento que facilita la incorporación a la condición de ciudadanos de todos los miembros de una comunidad.

La ciudad como contexto y agente educativo ofrece múltiples oportunidades para participar en su vida cotidiana. En este contexto "educación", “ciudadanía” y

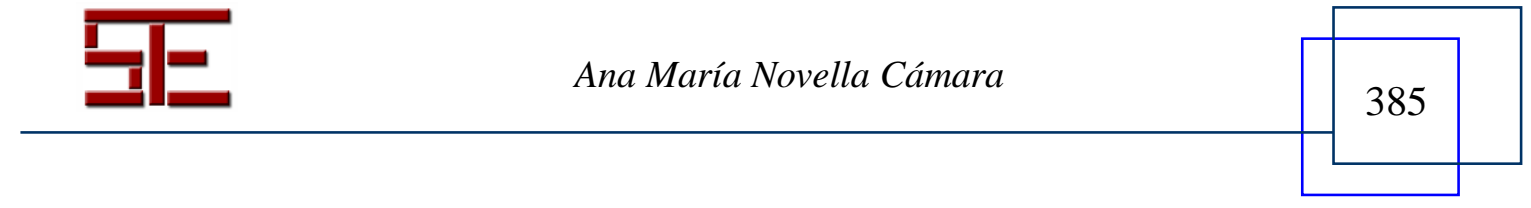




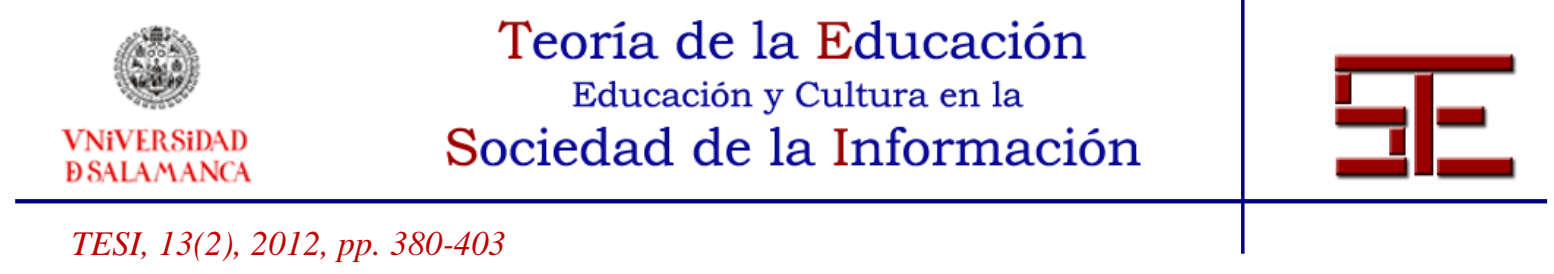

"participación" son elementos interdependientes que están en permanente relación y se retroalimentan dando forma a los proyectos educativos de ciudad. Ahora bien, hace falta que esta participación vaya a más y se materialice en prácticas concretas que permitan el ejercicio de los derechos civiles de los niños, su reivindicación y su formación integral como ciudadanos desde acciones ciudadanas concretas. Estas prácticas se han de diseñar teniendo en cuenta que la participación infantil no sólo es un derecho, sino que tiene diferentes implicaciones socio-psico-político-educativas que buscan la autonomía del sujeto. Hemos de impulsar el concepto de participación infantil desde su carácter multidimensional para que las prácticas educativas de este modo potencien al máximo la autonomía ciudadana de los niños y las niñas.

\section{3.- LA PARTICIPACIÓN INFANTIL COMO CONCEPTO DIMENSIONAL}

La incorporación del niño en su cotidianidad de una forma participativa pasa por diseñar proyectos compartidos y significativos para todos y todas, por definir responsabilidades, por transferirlas progresivamente, por establecer espacios de diálogos constructivos, por aprender a participar participando, por establecer compromisos compartidos... Para que las cosas sean diferentes, hace falta que todos y todas seamos conscientes de que los niños son responsables del aquí, del hoy y del ahora. Y nosotros, los teóricamente adultos, hemos de asumir la responsabilidad de desarrollar oportunidades para que así sea, y se debe hacer de una forma comprometida con la formación personal y ciudadana de los niños. No puede ser una iniciativa aislada delegada a la escuela o a la administración pública, sino que todos y todas debemos hacerla posible desde los principios democráticos que compartimos.

El niño no sólo tiene la oportunidad de ser cada vez más competente en participación, sino que a la vez tiene la oportunidad de construir su representación como persona autónoma altamente activa con responsabilidades y con competencias para poder definir los proyectos personales y para implicarse en los proyectos colectivos. Alcanzar esta máxima implica tener como referencia un concepto de participación infantil complejo y multidimensional que es el producto de las sinergias de las siguientes dimensiones que se retroalimentan unas a las otras y que incluso alguna vez podrían llegar a confundirse.

Pero todas ellas buscan la formación de la autonomía de la persona para la construcción de su identidad. La siguiente gráfica representa las dimensiones que conceptualizan la participación infantil, que a continuación analizaremos, y que son: representación de la infancia, experiencia educativa, principio que impulsa el desarrollo, construcción de valores democráticos, contenido formativo de la Educación para la Ciudadanía, ejercicio

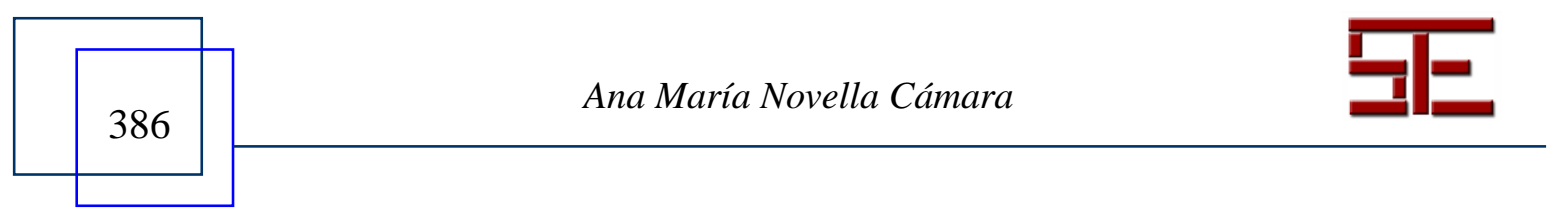




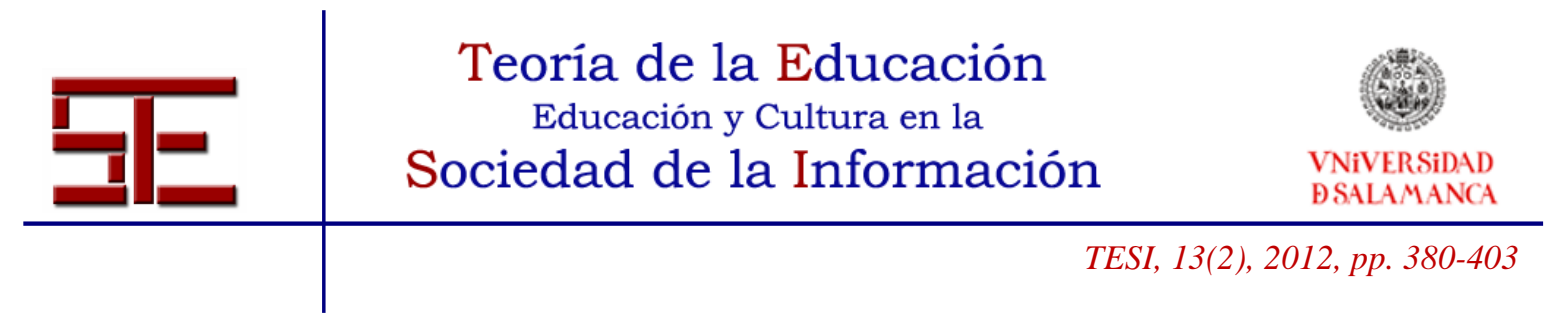

y formación política y, por último, pero no por ello menos importante, como pasión y emoción.

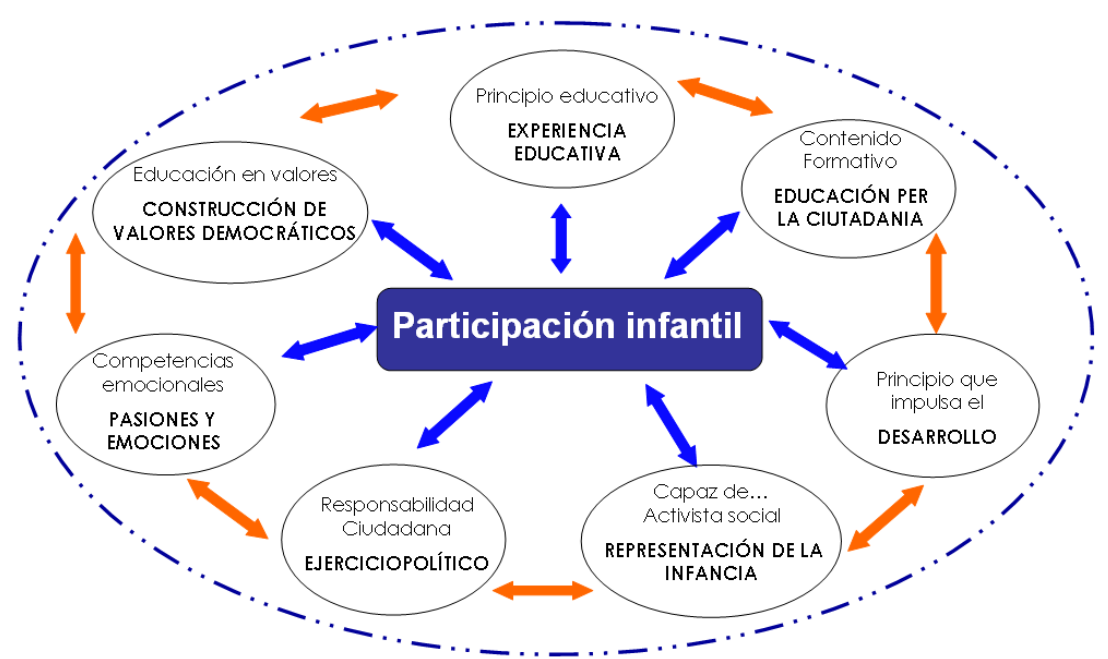

Gráfico 1. Dimensiones del concepto de participación infantil.

\section{1.- Dimensión "Representación de la infancia"}

Uno de los elementos que intervienen en la definición de la participación de los niños es la representación social que tenemos de éstos. Entre las concepciones que a lo largo de la historia se han establecido de la infancia están aquellas que los representaban como "el menor", "el todavía no", "el ciudadano del mañana"... A finales de los noventa, surgió todo un movimiento alrededor de reconocer el protagonismo de los niños en relación a la participación, sería el que se conoce como Participación "Protagónica". O paradigma del protagonismo. El concepto de protagonismo infantil designa el proceso social por el cual los niños deben tener un rol principal en su propio desarrollo y en el de su comunidad, garantizando así la realización plena de sus derechos, atendiendo a su interés superior (Gaytán, 1998, 86). Desde este punto de vista, surge la necesidad de redefinir gran parte de las representaciones relativas a la infancia, las relaciones sociales y su rol.

Se da la contradicción en culturas que reclaman la igualdad de derechos a todos los seres humanos que algunos derechos de los niños no están garantizados en base a sus menores conocimientos o a su edad, desaprovechando aquellas contribuciones que los niños pueden aportar a la sociedad a partir de sus pensamientos, sentimientos, juicios, etc... (Cussiánovich, Alfageme, Arenas, Castro y Oviedo, 2001). Es decir, a partir de

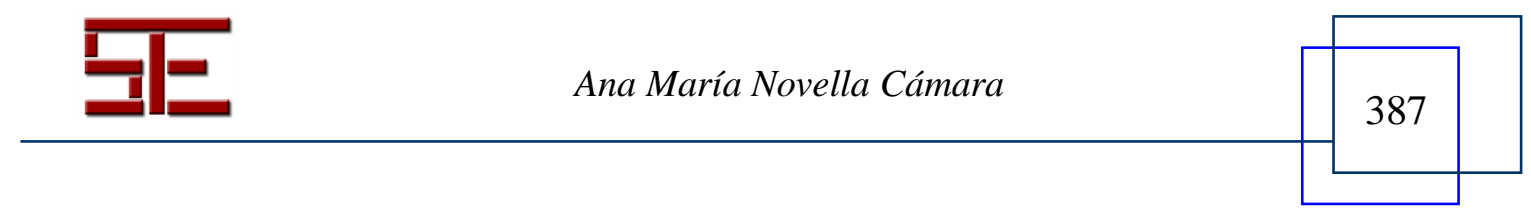




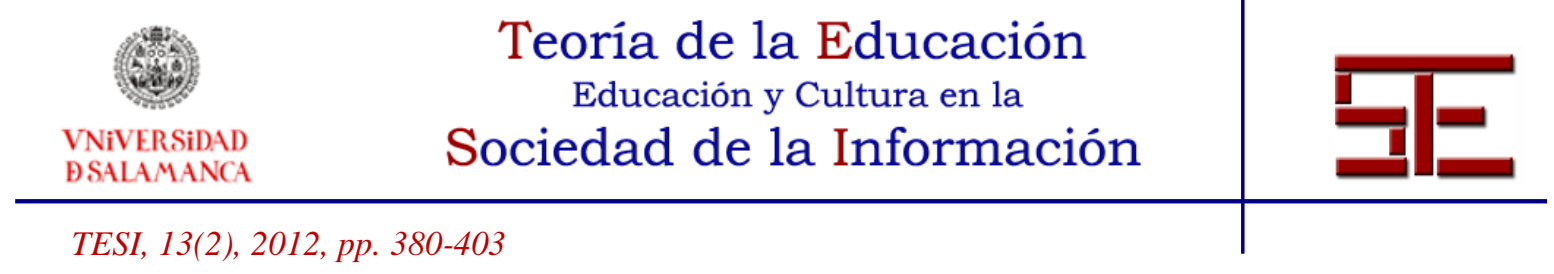

criterios de edad se produce una discriminación, mal entendiendo que la protección a la infancia implica su pasividad y dependencia del adulto. Cuando la mejor manera de protegerlos es promoviendo su autonomía. García y Micco (1997) explican como la normatividad democrática excluye a los niños menores de edad de la ciudadanía plena por el hecho de considerar que no pueden juzgar adecuadamente sus intereses y el propio bien. Este hecho, sin embargo, no quita que los niños se hayan de incorporar progresivamente a las prácticas democráticas, asentando así bases hacia una cierta teoría de la pre-ciudadanía que considera los niños como objetos y sujetos de preocupación democrática.

Ahora bien, las nuevas propuestas sobre el protagonismo y la participación de los niños abren nuevos retos y nuevas perspectivas que llevan implícitos nuevos ordenamientos culturales, con implicaciones tanto sociales, económicas como políticas. La participación protagónica de los niños funciona como eje articulador de nuevas formas de establecer las relaciones entre las personas y las de éstas con su entorno. Detrás de esta nueva concepción, hay la idea de que el niño está activamente involucrado en la construcción de su propia vida social, que ejerce su autonomía en las decisiones que toma y que es competente para participar en determinadas iniciativas ciudadanas. En este sentido, el adulto debe volver a definir sus funciones incorporando el concepto de agente potenciador de la autogestión y autodirección de los niños. Hace falta revisar las relaciones asimétricas y de poder, entenderlas como construidas culturalmente y, por lo tanto, modificables. El adulto ha de establecer un tipo de relaciones con los niños que permita potenciar el desarrollo de todos los individuos y del colectivo.

Estamos hablando de entender el protagonismo como derecho de todo ser humano y todo colectivo social. Así pues, esto implica la construcción de un nuevo modelo de infancia donde los niños deben tener la oportunidad y la posibilidad estructural y legal de poder tener influencia en los adultos y en la sociedad. Ser actores sociales implica tener autonomía en la toma de decisiones y disposición para contribuir en los proyectos sociales. Ahora bien, es conveniente dar un paso más a esta participación protagónica. Se plantea un nuevo reto. No sólo el niño ha de estar en el centro de la toma de decisiones, sino que se ha de impulsar su actividad, su capacidad de transformar. Los niños y las niñas son grandes activistas de las transformaciones sociales. Su protagonismo les ha de posibilitar cambiar su realidad próxima. De poco sirve el protagonismo si no se visualizan los efectos o consecuencias de éste. La representación del niño como ciudadano activo pasa por la capacidad de cambio de la realidad próxima, transformaciones específicas y pequeñas que permiten reconocer el valor de la participación. Transformaciones que van más allá de la ciudad o de la cotidianidad,

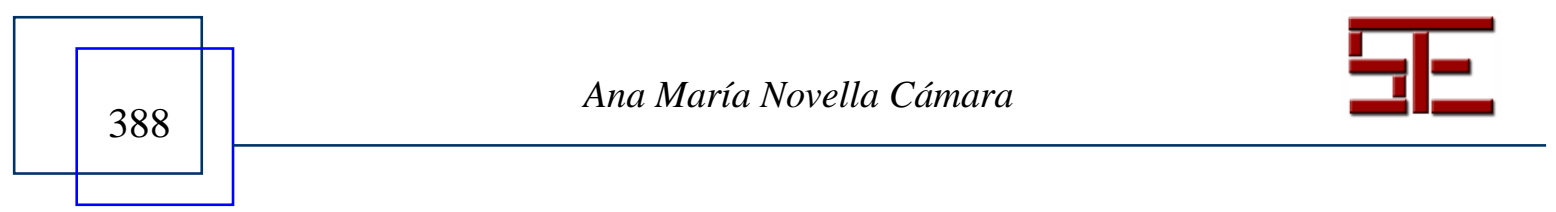




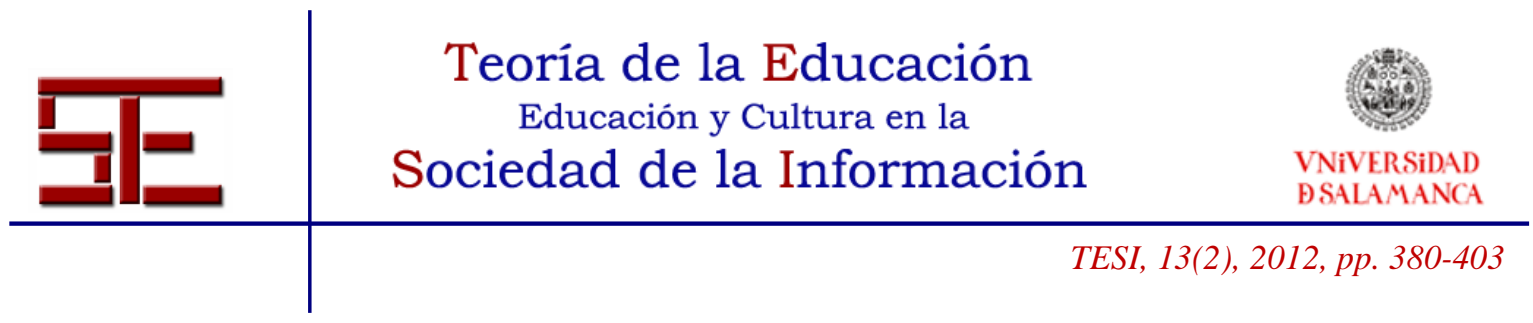

transformaciones que tienen que ver con reconocer su autonomía de hacer y transformar. Transformaciones en el "yo" ciudadano y "nosotros" ciudadanos.

Si reconocemos a los niños como activistas de las transformaciones sociales estamos reconociendo, y alimentando, su autonomía de ciudadano activo.

\section{2.- Dimensión "Experiencia educativa"}

La representación de la infancia incide en el diseño de las experiencias educativas y en las relaciones que se establecen en ellas. La participación de los niños ha sido, y es, uno de los referentes en el marco de las pedagogías activas. Éstas han contribuido con grandes aportaciones a la práctica educativa que defiende la participación como principio educativo, como valor que hace falta defender y como metodología para favorecer el crecimiento personal y la construcción de una comunidad democrática.

El concepto "participación" es un principio trascendente en la historia de la Pedagogía. Ésta, en el siglo XX, estuvo impregnada por la superación de una educación tradicionalista, dominada por prácticas autoritarias, donde la represión, el castigo, las verdades absolutas, la rectitud y la sumisión de la persona a aquello establecido eran principios que regían las instituciones y relaciones educativas. En contraposición a todo este modelo de educación, y sociedad, surgieron diferentes movimientos educativos que pretendían luchar contra la represión, ampliar los espacios de libertad y defender la participación. Éstos serían los estándares de todo un movimiento de pedagogos y psicólogos que se sitúan en el marco de las denominadas "pedagogías antiautoritarias" y que se proponían apoyar los cambios sociopolíticos que se iniciaban para superar los efectos de la Segunda Guerra Mundial, las incidencias de la revolución soviética y la desconfianza de las incipientes democracias que eran continuidad de Estados autoritarios y clasistas.

La defensa de la libertad es la máxima de las pedagogías antiautoritarias. La educación, dentro de esta perspectiva, tiene la finalidad de formar personas libres que puedan expresar los valores positivos de su naturaleza. Y lo harán si se permite que experimenten un régimen de libertad en el marco de la convivencia. A continuación, se presentan brevemente algunas de las ideas principales de los autores asociados a la pedagogía antiautoritaria:

- La defensa de la bondad del ser humano en un entorno libre y espontáneo. Rousseau defiende la infancia como una etapa evolutiva que se debe respetar y durante la cual se debe permitir que se disfrute con libertad, sin prisas por superarla, y sin la voluntad de llenarla de informaciones y pautas.

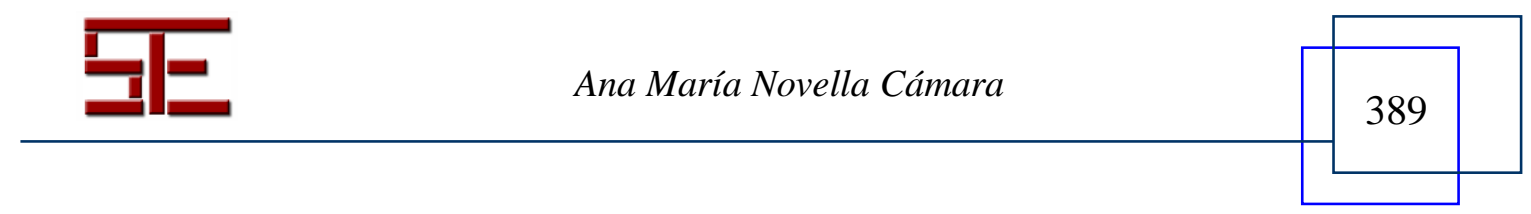




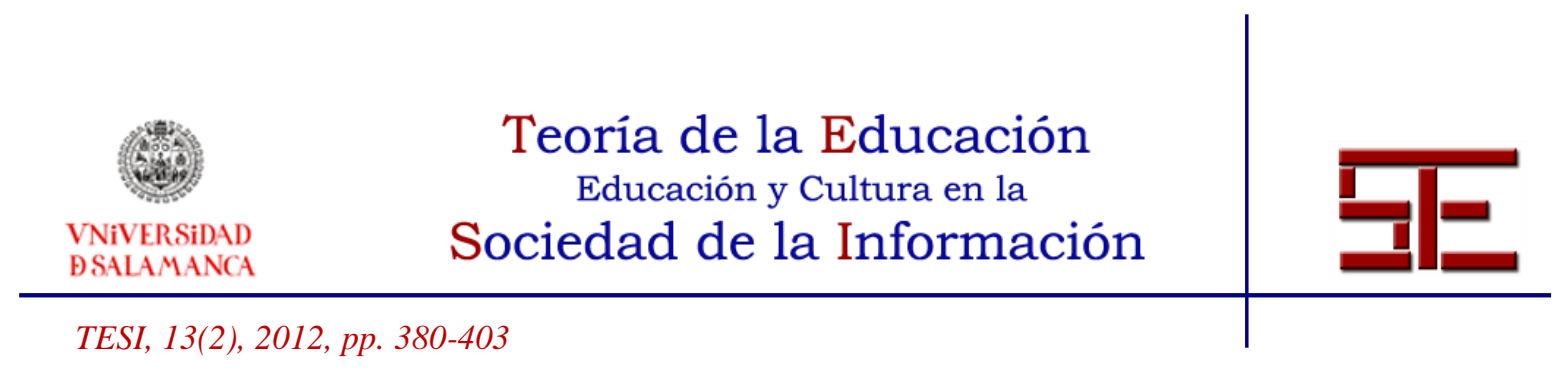

- El optimismo en la naturaleza humana: autonomía y libertad. Neill apostaba por una vida emocional equilibrada. La escuela de Summerhill fue la institución donde Neill desarrolló sus ideas, fundamentadas en la libertad y el autogobierno. El deseo de aprender era la garantía del aprendizaje y era más efectivo que cualquier otro método pedagógico.

- El educador no directivista. Carl R. Rogers fue uno de los defensores principales del valor de las relaciones interpersonales en la configuración de la personalidad, en la configuración del yo desde la no-directividad. El perfil del educador no directivo se caracteriza por: la comprensión empática, la autenticidad o congruencia y la consideración positiva incondicional desde la aceptación y confianza.

- La pedagogía institucional o autogestión pedagógica. Freinet es el gran promotor de la asamblea como la instancia privilegiada para hacer el análisis institucional y es dónde se abre todo un espacio para la creatividad, la toma de decisiones, su puesta en práctica y su posterior evaluación y modificación. En definitiva, es el momento de la autogestión.

- Autonomía y responsabilidad comunitaria. Lawrence Kohlberg no es un autor relacionado con las pedagogías antiautoritarias, pero en sus experiencias educativas se fundamenta la participación infantil, la ayuda no directiva de los educadores y todo el clima institucional caracterizado por valores como la autonomía, la comunidad y la justicia. Demostró que los sistemas de participación, de no-dirección y de autogobierno son caminos esenciales para la formación moral de las personas.

Las aportaciones de estos autores han aportado elementos innovadores para la reflexión pedagógica y la práctica educativa fundamentada en la educación para la libertad y la participación de los niños y las niñas. Sus aportaciones han supuesto grandes contribuciones que caracterizan las experiencias educativas como espacio para la formación autónoma y ejercicio de la libertad individual y colectiva.

En la defensa de una educación no autoritaria, que en la actualidad llamaríamos una educación democrática, está el origen de la participación de los niños. La participación infantil ha de ser una experiencia educativa donde los niños se implican siendo intérpretes críticos de su cotidianidad y donde el diálogo y la acción comprometida son pilares fundamentales. Son experiencias donde hay un reconocimiento del valor de la convivencia y del sentimiento de pertenencia a la colectividad; donde se construye el sentido autónomo de la disciplina; donde se desarrolla una fuerte autonomía de la

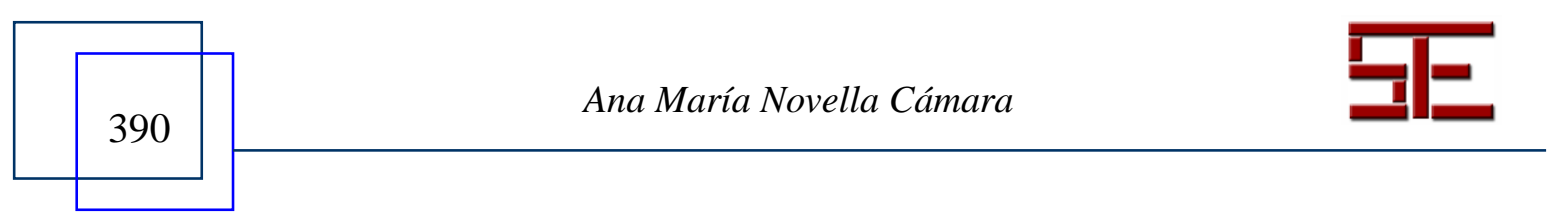




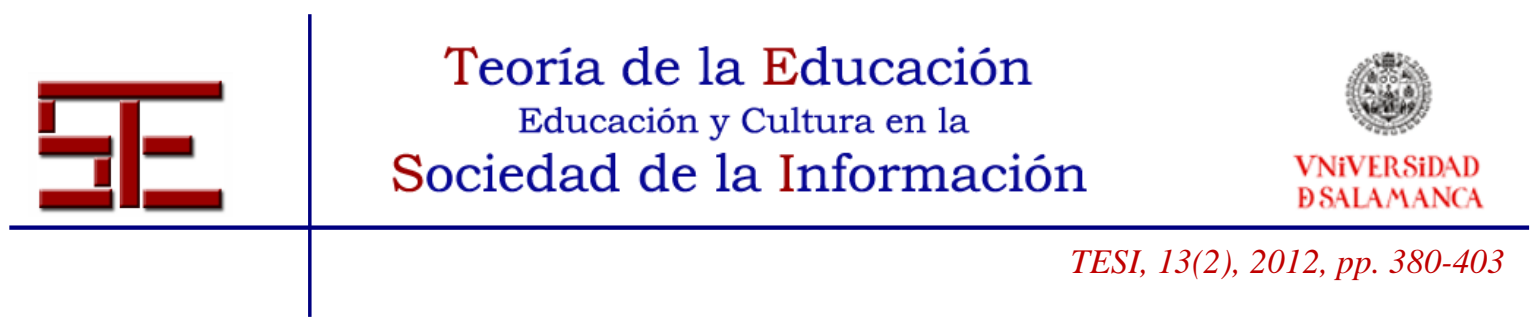

voluntad que ayuda a gestionar la confrontación entre colectividad y la individualidad; donde la deliberación es el mecanismo para la concreción del activismo transformador y donde la finalidad máxima es ser felices y hacer un "mundo" un poco mejor.

\section{3.- Dimensión "Principio que impulsa el desarrollo"}

Desde esta propuesta, se entiende que existe una relación muy estrecha entre el desarrollo de las personas y las experiencias educativas. Este posicionamiento defiende que los conocimientos y las habilidades aprendidas en situaciones educativas revierten en niveles más altos de desarrollo. Los procesos educativos, según Franch (1985, citado en Trilla, 2000), consisten en: "aprender a actuar", que quiere decir adquirir instrumentos para intervenir en la misma realidad; "aprender a relacionarse", a adquirir las capacidades para interactuar con los otros, y aprender "a pensar", a construir una forma específica de interpretar la realidad. Esos aprendizajes en un marco sociocultural son el motor del cambio, de avance y maduración desde donde interiorizar aquello que se ha aprendido. Implicarse en experiencias educativas implica participar y desarrollar capacidades que favorecen la responsabilidad personal y social. Por eso, no podemos obviar, que la participación es un concepto central para la psicología del desarrollo y la psicología de la educación.

El desarrollo es el resultado, entre otras cosas, de los saberes que se apropia el individuo en las prácticas sociales y educativas en las que participa. Por tanto, implica la participación de las personas en patrones de actividad cada vez más complejos que le impulsen a adoptar roles específicos y a dominar autónomamente aspectos concretos de la cultura.

A partir de la noción de desarrollo "mediado" se está atribuyendo gran importancia a los componentes sociales y culturales del comportamiento y desarrollo de las personas. Desde esta perspectiva, la actividad de las personas está inscrita siempre en un marco culturalmente organizado, que les diferencia del comportamiento de otras especies. Las costumbres, creencias, conocimientos, valores, pautas de actividad, instituciones, etc., desarrolladas a largo de la historia de los grupos humanos "median" entre el individuo y su entorno, por esto el comportamiento y el desarrollo es siempre "mediado" cultural y socialmente.

Ahora bien, la importancia atribuida a los factores sociales y culturales no supone negar el papel de los componentes biológicos del desarrollo. Además de la información genética, que genera el desarrollo biológico, cada persona dispone de una herencia cultural de su propio grupo que condiciona su proceso evolutivo. Así desde esta perspectiva el desarrollo se puede caracterizar como un proceso mediado social y

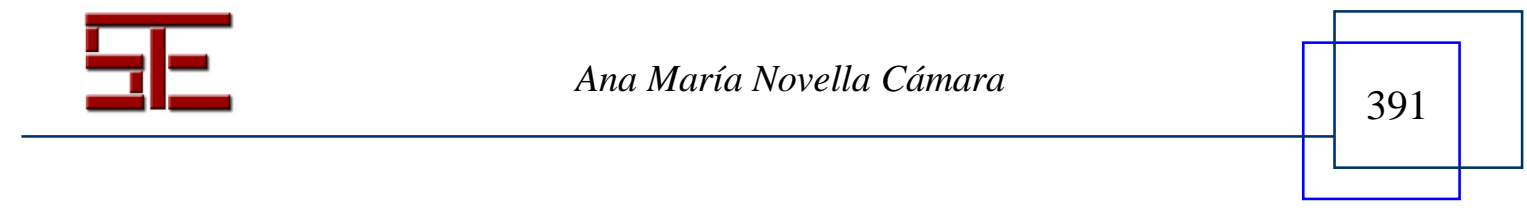




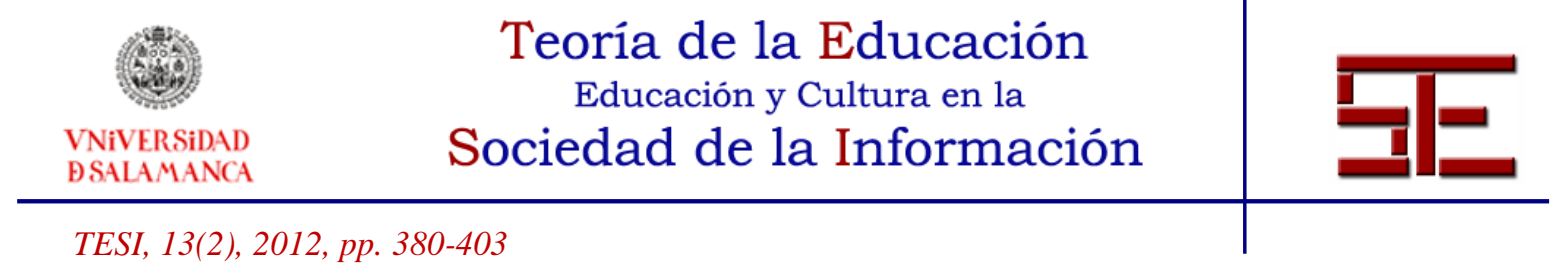

culturalmente, con posibles elementos de carácter universal, pero también con elementos vinculados a la especificidad cultural de los diferentes grupos. Entre los autores de la perspectiva sociocultural del desarrollo se encuentran, entre otros, Vigotski, Wallon, Wertsch, Bruner y Rogoff.

La interacción social con otras personas, y en particular, la participación en situaciones interactivas en las que recibimos el apoyo y la ayuda explícita de miembros de nuestro grupo social más expertos y competentes, constituye uno de los factores más importantes por explicar el desarrollo humano. En este contexto se define la educación como el conjunto de prácticas sociales que tiene una cultura mediante las cuales determinados miembros expertos del grupo, o al menos más competentes, intentan que otros miembros menos expertos adquieran instrumentos y capacidades necesarias para participar de manera activa en el grupo. En este sentido, la participación se convierte en el motor básico del desarrollo y del crecimiento humano.

Las personas participan a largo de su vida en diferentes contextos que les permiten asumir roles diferentes, aprender patrones de comportamiento y de relación diversos. El potencial de una práctica educativa es su poder para ayudar al aprendiz a apropiarse del contenido y para asegurar el dominio autónomo. Ya hemos dicho que toda sociedad ayuda a sus miembros a asimilar la experiencia culturalmente organizada y a convertirse en miembros activos y en agentes de creación cultural, así se favorece el desarrollo personal en el si de la cultura del grupo haciéndolos participar en un conjunto de actividades que constituyen lo que denominamos educación.

Por último, citar la propuesta de Rogoff (1997), que desde un enfoque sociocultural plantea tres niveles de análisis de los procesos de desarrollo implicados en la participación conjunta de los individuos en las prácticas socioculturales. Estos diferentes planos corresponden a la apropiación participativa, la participación guiada y el aprendizaje:

- La apropiación participativa da cuenta de procesos individuales y personales, del cambio en el individuo que resulta de la propia participación, gracias a su implicación en actividades que les ayudarán a afrontar otras situaciones futuras parecidas.

- La participación guiada pone énfasis en los procesos interpersonales, en los procesos de observación y de implicación mutua entre individuos que se comunican en cuanto que son participantes de una actividad cultural y significativa. Algunos de los aspectos claves en la participación guiada son el concepto de guía (que se refiere a la ayuda y dirección que ofrecen la cultura, los

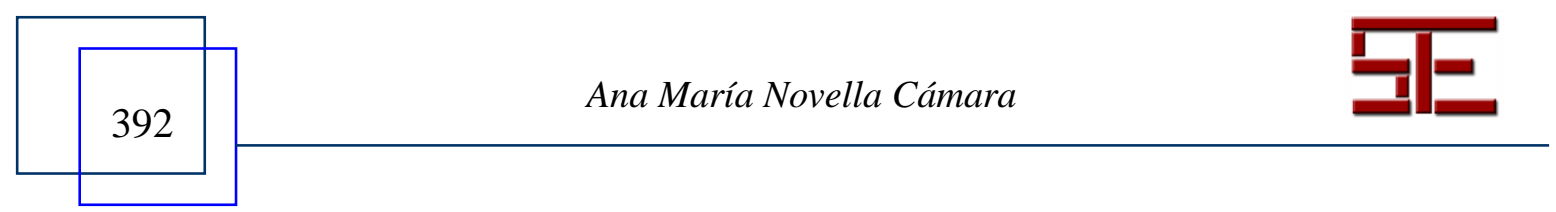




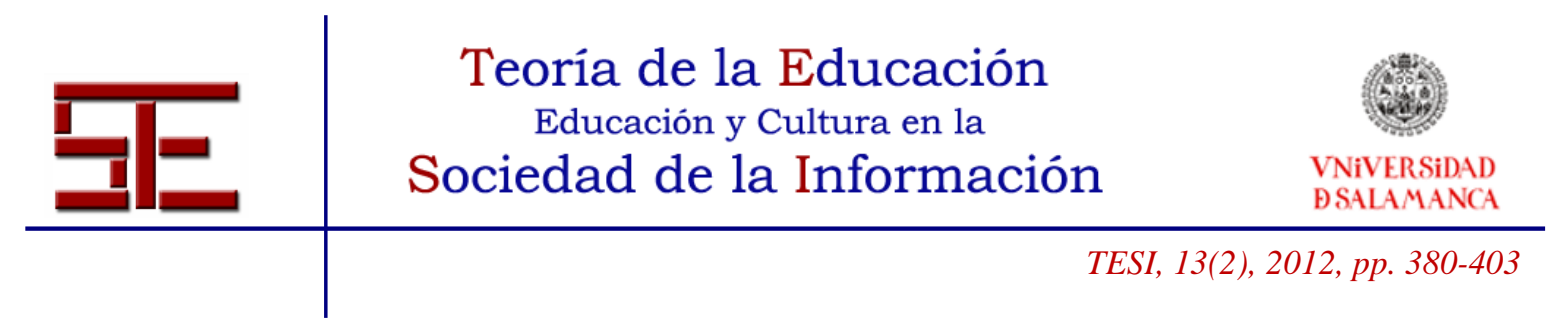

valores y los otros), la importancia de la comprensión de los objetivos por parte de los participantes, la estructuración de las situaciones y la comunicación y coordinación de esfuerzos entre los miembros del grupo.

- El aprendizaje como aspecto cultural y comunitario del proceso en el cual los individuos participan activamente y con otros en actividades culturalmente organizadas, con el propósito de hacer más madura la participación de los miembros participantes más inexpertos. En este nivel se pone especial atención a la actividad, en términos de organización institucional y de prácticas comunitarias.

Aún cuando se ha tratado cada plano o nivel por separado, realmente pertenecen a diferentes focos de atención del mismo fenómeno. Se trata de niveles inseparables y mutuamente constituyentes a partir de los que se organizan y estructuran actividades participativas (Rogoff, 1997). La participación de los niños es una oportunidad para el desarrollo personal, social y comunitario.

\section{4.- Dimensión "Construcción de valores democráticos"}

La participación como actividad sociocultural, conlleva la convivencia dentro de los grupos sociales y de las comunidades. Esta convivencia necesita el desarrollo de referentes compartidos y solidarios que favorezcan la construcción de ideales democráticos fundamentados en el diálogo y la acción conjunta. Pero, como hemos visto en la dimensión anterior, las experiencias educativas mediadas impulsan en un todo el desarrollo personal y social. En este desarrollo, juegan un papel muy importante los valores y su formación. La formación en valores no es una imposición de ideas y de formas de comportamiento ni una práctica reproductora que está prevista con antelación, ni se descubre por casualidad. Es una construcción que no se puede hacer en solitario ni al margen de una historia, ni desprovista de unos antecedentes sociales y personales. Esta construcción permite a la persona definir su proyecto de vida y su propia escala de valores en el marco de una matriz de valores y referentes democráticos compartidos culturalmente. La educación en valores, ha de favorecer la construcción de la identidad personal en el marco del "nosotros-yo" y del "yo-nosotros".

Hoy en día, la transmisión de valores es un elemento inherente a las relaciones humanas y en el si de las sociedades. Las relaciones educativas, como relaciones humanas, son realidades densas de valor. Así, indiscutiblemente, entendemos que la participación infantil es una práctica educativa que favorece la construcción de valores democráticos. Entre las perspectivas que defienden la formación de valores, nos posicionamos ante el modelo basado en al construcción dialógica de la personalidad moral (Puig, 1996). Es

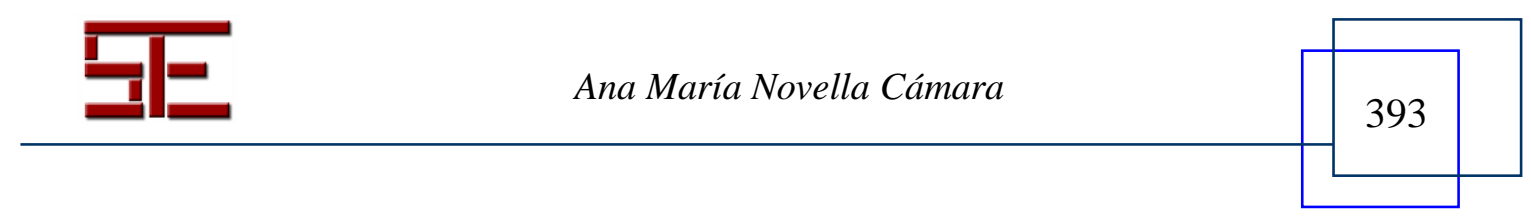




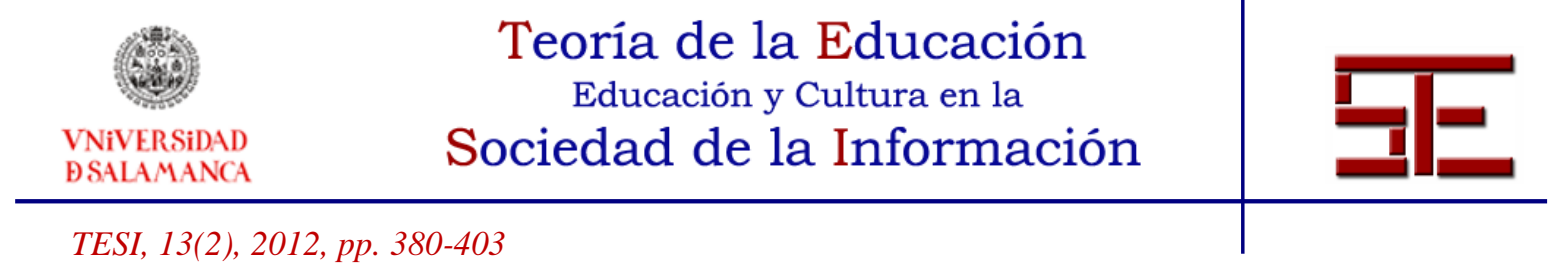

un modelo que reconoce la autonomía del sujeto, dando valor a su capacidad para tomar decisiones y para actuar según unos criterios internos libremente escogidos. Con todo, destaca el papel que los otros tienen en la formación de cada individuo. Este modelo no defiende determinados valores absolutos, pero tampoco es relativista. Se trata de una construcción racional, autónoma y dialógica de los valores.

En la construcción de la personalidad intervienen elementos socioculturales preexistentes que nos muestran los caminos, pero es un proceso en que interviene de una forma responsable, autónoma y creativa cada sujeto. La máxima de este proceso es lograr una forma de vida satisfactoria para la persona en un entorno social, cultural e histórico determinado. Puig (1996) propone tres elementos y dinamismos que intervienen en este proceso formativo:

- Experiencias de problematización moral. Las experiencias de la vida cotidiana son el contenido principal a partir del que hace falta trabajar y reflexionar. Aquello que experimentamos nos ofrece un conjunto de información, de emociones, de posicionamientos..., que es el material principal a partir del que configuramos nuestra personalidad. Estamos rodeados de vivencias significativas, ante las cuales no somos indiferentes, puesto que suponen retos y desafíos, que abren nuevos cuestionamientos ante los que se deben tomar decisiones y posicionamientos que forman y acompañan la configuración de nuestra personalidad. A las prácticas de formación en valores, les corresponde la responsabilidad de identificar y de hacer contenido de trabajo las diferentes experiencias en que la persona está inmersa y participa de forma tan activa y significativa. Son experiencias que para la persona suponen conflictos de valor o controversia, puesto que, de alguna manera, les cuestionan su posicionamiento inicial.

- Instrumentos de la conciencia moral autónoma. Ante las experiencias de problematización, las personas tenemos una serie de recursos, unos procedimientos de la conciencia moral y unas guías culturales de valores que nos permiten realizar acciones sociomorales para poder abordar los problemas que emergen en las experiencias morales. Estos recursos se han formado a lo largo de la evolución filogenética y sociocultural. Los procedimientos de la conciencia moral son los instrumentos psicológicos que nos ayudan en el análisis de los procesos morales y que permiten la deliberación y la dirección moral en situaciones de conflicto. Estas herramientas permiten trabajar sobre realidades controvertidas. Los instrumentos de la conciencia moral son disposiciones que dan a la conciencia la capacidad para dirigir por sí misma la vida moral de cada

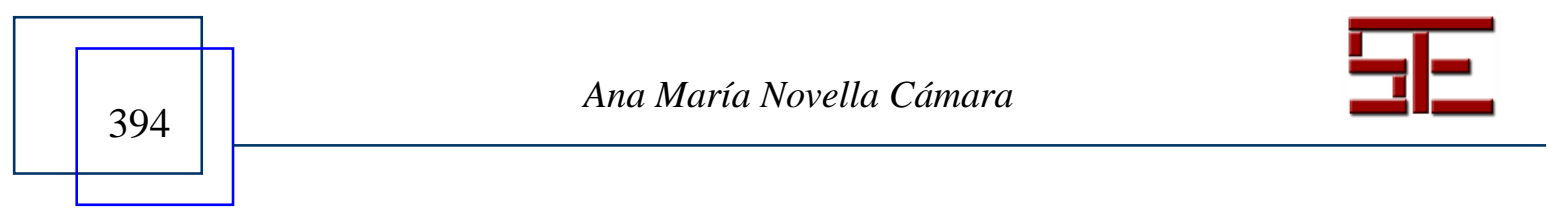




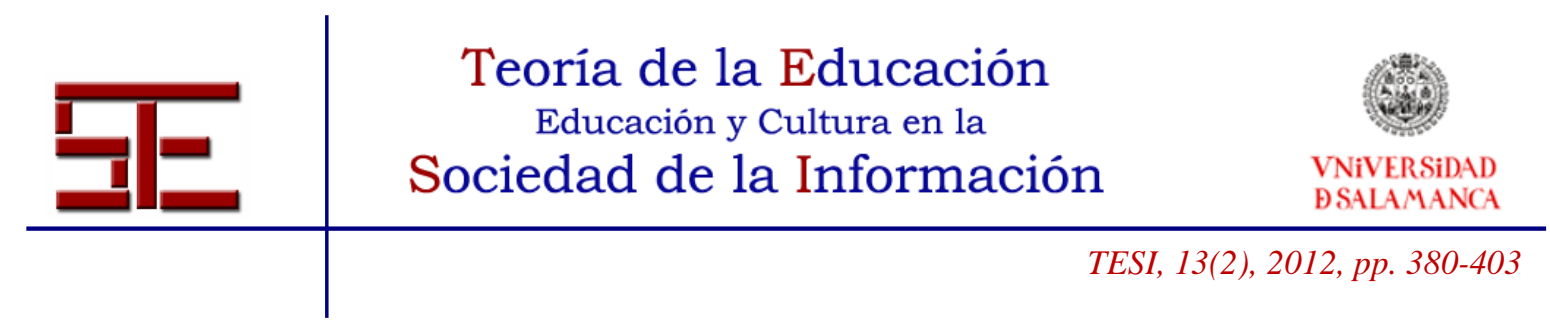

sujeto. Éstos son: el autoconocimiento; el conocimiento de los otros; el juicio moral; la capacidad para la comunicación, el diálogo y la deliberación; la comprensión crítica; la acción, y la autorregulación. Finalmente, hace falta decir que todos estos elementos no pueden actuar de manera aislada, sino que son de naturaleza sistémica, puesto que se influyen mutuamente, se interrelacionan y no operan de manera independiente.

- Guías de valor. Son entidades simbólicas que pautan las formas de vida de una colectividad y le dan significado. Son realidades informativas-significativas que modelan formas de vida y de convivencia entre individuos. Son productos culturales que, a manera de recursos o instrumentos, intervienen en la acción socio-moral con la finalidad de conseguir la máxima eficacia en la resolución de las controversias de valor que plantean las experiencias. Los sujetos recibimos de forma más o menos consciente elementos de una cultura moral que nos da guías para el análisis y la acción. Las guías de valor no son estáticas, sino que están sometidas a procesos de cambio, puesto que se modifican, se reconstruyen y se transforman.

La participación de los niños en las situaciones de la vida cotidiana -donde las experiencias de problematización moral son contenido de análisis y deliberación para planificar una respuesta y/o acción transformadora- implica el uso de procedimientos y guías de valor que orienten esta acción. La implicación en proyectos compartidos desde el ejercicio de la palabra y el compromiso con la acción supone el desarrollo de los instrumentos de la conciencia moral y el cuestionamiento-consolidación de las guías de valor.

Las prácticas educativas que pretenden promover la participación de los niños deben tener en cuenta estos tres dinamismos expuestos.

\section{5.- Dimensión "Educación para la Ciudadanía"}

Nos formamos como ciudadanos y ciudadanas en la medida que tenemos la oportunidad de ejercer nuestra participación en el marco de los grupos y comunidades en que estamos implicados. La educación para la ciudadanía representa un elemento esencial en la construcción de valores centrados en promover la participación activa en todos los ámbitos de la vida social. La educación para la ciudadanía es definida como el conjunto de prácticas y actividades diseñadas para ayudar a todas las personas, niños, jóvenes y adultos, a participar activamente en la vida democrática, aceptando y practicando sus derechos y responsabilidades en la sociedad. Se trata de incidir de una forma más intencional, desde la correponsabilidad de todos los agentes educativos, en formar

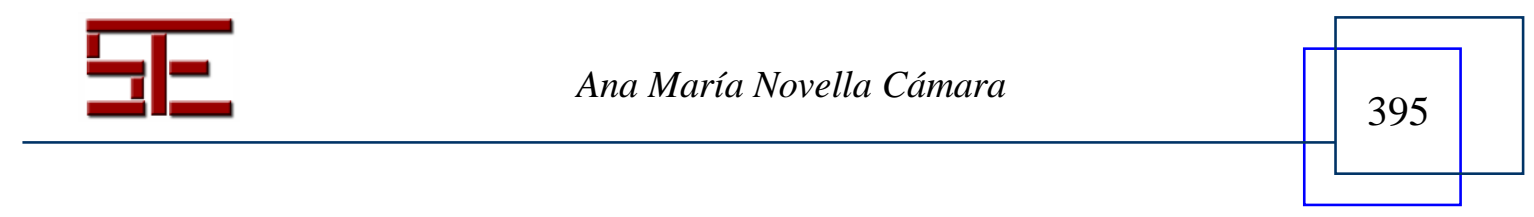




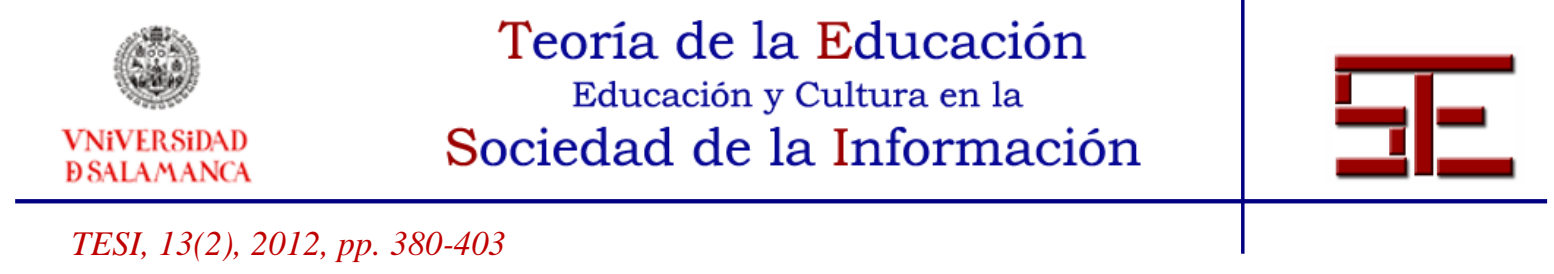

ciudadanos más competentes cívicamente y más comprometidos, mediante la participación en las responsabilidades colectivas.

Se apuntaba al inicio de la comunicación que la ciudad es un contenedor de recursos educativos y un agente educativo. A la vez que es un marco contextual denso de valores y contravalores. Pero, es necesario resaltar en el marco de la educación para la ciudadanía otro elemento importante, que es aquello que se aprende. "Se aprende de la ciudad y, a la vez, se aprende la ciudad" (Trilla, 1998, 34). Se ha de garantizar que los niños participan de su ciudad aprendiéndola y transformándola.

La ciudad como contenido de aprendizaje supone una realidad densa de informaciones, de acontecimientos y vivencias que rodean el ciudadano como un perfume. En la dimensión anterior hemos visto como, en su papel de agente, la ciudad transmite valores y contravalores. Pero la ciudad como contenido es algo más que se da en los procesos de aprendizaje que sobre ella hace el ciudadano y que desde ella misma se pone al alcance del ciudadano. Estamos hablando de todo aquello que se transmite en la relación directa y en el día a día. La educación para la ciudadanía implica aprender cómo moverse en la ciudad autónomamente y cómo ejercer la ciudadanía responsable y comprometida.

En esta dimensión se reconocen los aprendizajes que el ciudadano experimenta en primera persona. Pero, a la vez, se está señalando la ciudad como el contenido en que se instruye y sobre el cual se debe ser consciente para evitar los límites y transformarlos en potencialidades. Entre los aprendizajes que debería garantizar la educación para la ciudadanía, Trilla (1998) destaca: aprender la ciudad es aprender a utilizarla; aprender a leer críticamente; aprender a participar en su construcción; y aprender a aprender a la ciudad.

La ciudad como contenido de aprendizaje debe posibilitar que los diferentes colectivos de ciudadanos hagan cosas con sus contenidos, pero sobre todo que sean conscientes de su autonomía para el ejercicio de la ciudadanía. Los contenidos fundamentales que transmite la ciudad tienen que ver con la participación en un proyecto común y la corresponsabilidad. Estos aprendizajes hacen posible que los ciudadanos se impliquen en la ciudad ejerciendo su ciudadanía y, por lo tanto, que se aproximen a otros contenidos que les permitirán ampliar su matriz de referencia y sus herramientas para la construcción de conocimiento (saber, saber estar y saber ser).

Los instrumentos que permiten a la ciudad mostrarse como contenido tienen que ver con diferentes estrategias participativas que se diseñan para hacer cosas en el marco de la ciudad y para transformarla. Por ejemplo: los consejos ciudadanos, las consultas

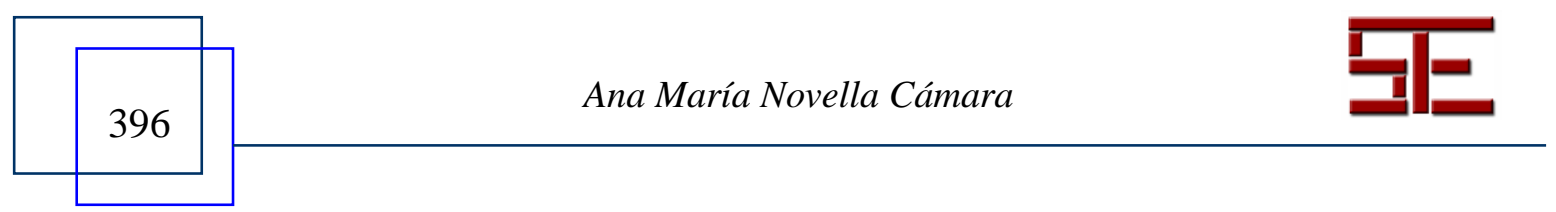




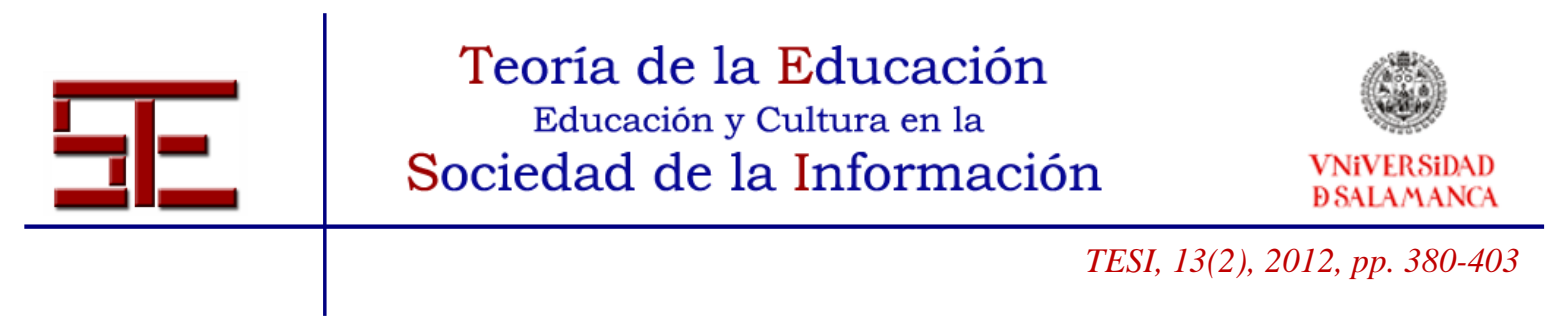

participativas, los proyectos compartidos, las comisiones de seguimiento... También hay otras estrategias que se proponen para instruir en la ciudadanía desde las propuestas curriculares de la escuela. Sea de la forma que sea, la ciudad educadora se pone a la altura de los ciudadanos para que éstos puedan aprenderla de forma participada e integral. O quizás, simplemente, por degustación, como propone Adela Cortina.

A ser ciudadano se aprende como casi todo, y además se aprende no por ley y castigo, sino por degustación. Ayudar a cultivar las facultades (intelectuales y sentimentales) necesarias para degustar los valores ciudadanos es educar en la ciudadanía local y universal (Cortina, 1997, 218).

\section{6.- Dimensión "Ejercicio y formación política"}

La participación no es sólo una manera de hacer y organizar la vida colectiva, sino también una forma de hacerla deseable y óptima. Implica tener en cuenta los intereses y las necesidades de todo el mundo y, por lo tanto, lleva implícitos los valores de justicia, de solidaridad y de autonomía de los sujetos. El concepto de participación lleva implícita una dimensión política que no se puede obviar ni maquillar. Tomar parte en la vida pública de aquello que es colectivo es participación política, así como el hecho de promover acciones que están dirigidas a influir directa o indirectamente en las políticas. Esta dimensión de la participación, es una forma de profundizar en la democracia y/o de posibilitar actuaciones ciudadanas que limiten las decisiones de la Administración pública. Un ejemplo de esta concepción es la definición de participación dada por el sociólogo Manuel Castells (1986): "Proceso social mediante el cual el sistema de decisiones implícito en la planificación urbana se abre a la influencia de varios grupos y clases sociales así como a las diferentes tendencias políticas e ideológicas que tratan de representar estos grupos y clases".

Tomar parte en el proyecto de ciudad implica ejercer la ciudadanía desde su significado más profundo: la acción política. Ser ciudadano comporta ser sujeto de derechos políticos que interviene autónomamente, ejercitándolos, en el gobierno del país. Esta definición de ciudadano en el caso de los niños y las niñas se silencia, no se potencia sino que se invisibiliza.

Una de las consecuencias más importantes de la participación infantil se da lugar en los procesos más intrínsecos del desarrollo personal de cada niño o niña y el descubrimiento de su condición como ciudadano o ciudadana. Es una experiencia inolvidable, cargada de momentos únicos, que como veremos en la siguiente dimensión, están cargados de emociones y sentimientos. Los niños y las niñas participando en experiencias auténticas de ejercicio de la ciudadanía aprenden que sus opiniones se

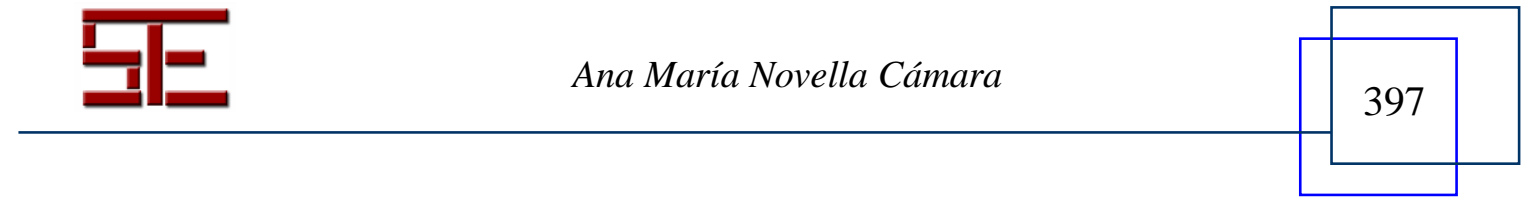




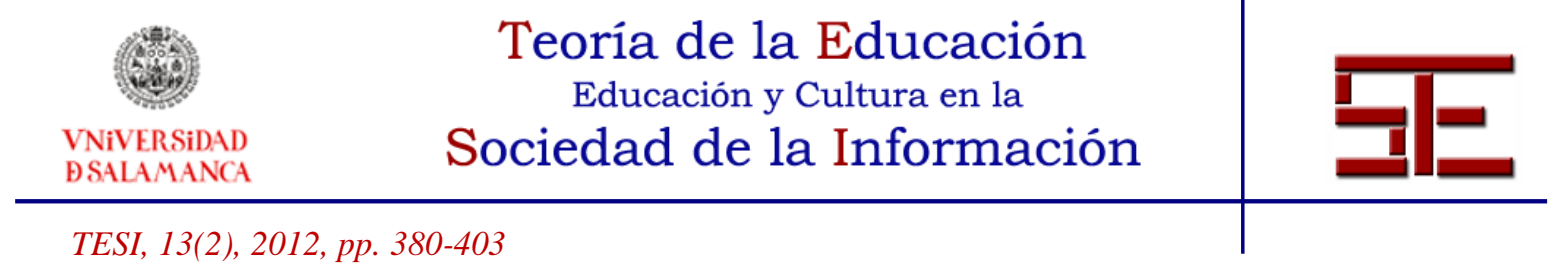

tienen en cuenta, que han desarrollado acciones que han transformado su cotidianidad. En el tiempo que se han implicado en la experiencia participativa, han construido su imagen de ciudadanos responsables y comprometidos con su ciudad. Sienten que forman parte de ella y que de sus actuaciones depende que ésta se transforme. El niño o la niña que está inmerso en prácticas participativas se siente reconocido como ciudadano/a y desde aquí construye su papel, su forma de relacionarse con la ciudad. Hay como un sistema de retroalimentación que hace que los niños y las niñas se reconozcan como ciudadanos con derechos y responsabilidades. La construcción del papel de ciudadano, de acuerdo con Cortina (1999), supone un doble juego para los niños. Primero, para que se sientan ciudadanos, la ciudad los ha de hacer sentir ciudadanos; y segundo, los niños han de participar de la ciudad autónomamente.

La participación política de los niños está implícita en su condición de ciudadanos. Pero, se ha de garantizar que las experiencias de participación infantil intensifiquen el ejercicio de la ciudadanía con su dimensión más compleja del ejercicio político que conlleva. Formarse para la ciudadanía implica desarrollar una cultura política más allá de la política representativa emplazada en el plano institucional y estructural. Supone ejercer desde edades muy tempranas la ciudadanía participativa en acciones concretas que conlleven una democracia participativa a través de la cual los niños incidan y transformen la realidad próxima y cotidiana. La autonomía política va más allá de los derechos civiles, implica reconocerse y comportarse como ciudadano activo.

\section{7.- Dimensión "Emocional y pasional"}

La participación tiene una dimensión emocional, podemos tomar parte sin sentirnos implicados. En las experiencias participativas se ha de poder impulsar el compromiso y la responsabilidad colectiva pilares del activismo y transformación de las ciudades desde su ciudadanía. Cuando las personas tomamos parte activa en proyectos colectivos no percibimos la situación ni la interpretamos del mismo modo, puesto que daremos sentido a la situación, y nos sentiremos más o menos implicados, en función de nuestras experiencias emocionales, reales o potenciales que dependen, a grandes rasgos, de nuestras necesidades y/o deseos. De esta manera, ante una misma experiencia participativa, cada persona puede interesarle participar por diferentes motivos y con diferentes intensidades. Pero aquello que no se puede obviar es que la participación tiene un sentido y significado para cada participante. Desde este sentir se implica y toma parte desarrollando la propuesta o proyecto que implicará una transformación personal y colectiva. El activismo y sentirse agente político con capacidad de transformar supone un reconocimiento personal que impulsa mayor implicación y participación.

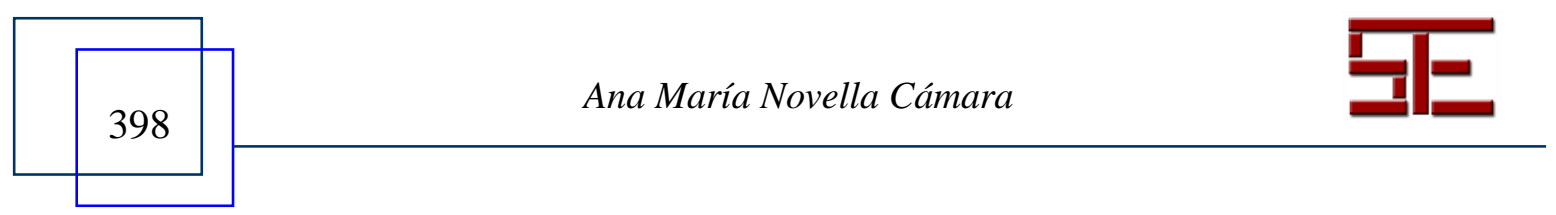




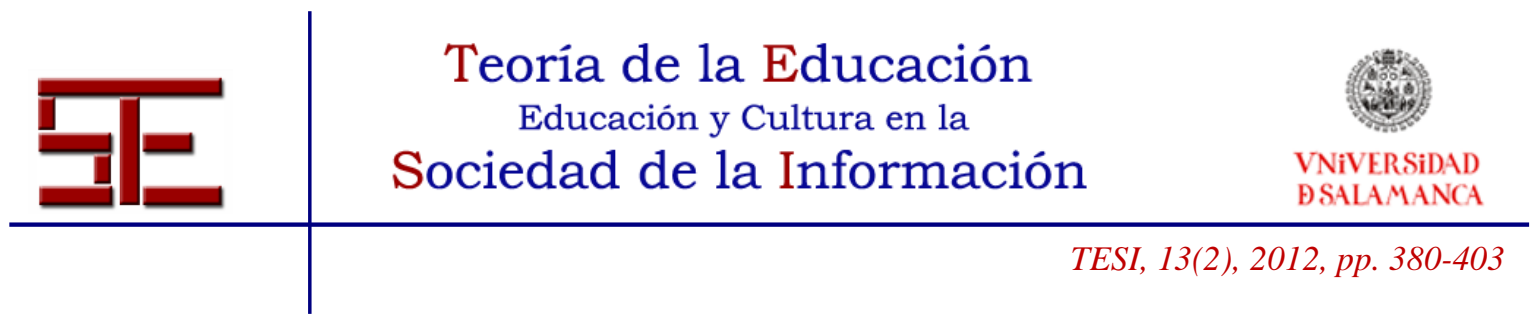

Las personas se implican en experiencias participativas en función de una motivación intrínseca y/o extrínseca. El ciudadano que participa por una motivación intrínseca, le sale de dentro, es una disposición natural y espontánea por sentirse competente y poder disfrutar de la experiencia a nivel individual y/o colectivo. Aquel ciudadano que participa por una motivación extrínseca, su implicación se ve promovida por el hecho de conseguir recompensas y reconocimientos externos.

Las emociones y pasiones se construyen desde la percepción del individuo y colectivo, a partir de la percepción de funcionalidad y utilidad de la participación desde el reconocimiento de la evolución de su cotidianidad. Reconocerse autónomo y reconocido por el entorno hace que la participación amplifique la confianza y la autoestima. La participación se intensifica y disminuye en función del plano de las emociones que moviliza.

La implicación personal en experiencias participativas genera un gran impacto en quien participa, provocando sentimientos de afecto, solidaridad y empatía hacia la ciudad y el derecho de los niños a participar. Las acciones auténticas de participación en el seno de la ciudad por parte de los niños y las niñas generan en ellos actitudes de compromiso y responsabilidad que invitan a una participación cada vez más competente y autónoma.

Estas dimensiones, junto con la forma de entender la educación, la participación y el contexto educativo, implican un conjunto de sinergias que orientan el diseño y desarrollo de la participación con la finalidad de potenciar la construcción de la identidad en pro de la autonomía ciudadana. La siguiente gráfica recoge la complejidad conceptual y práctica de la participación infantil.

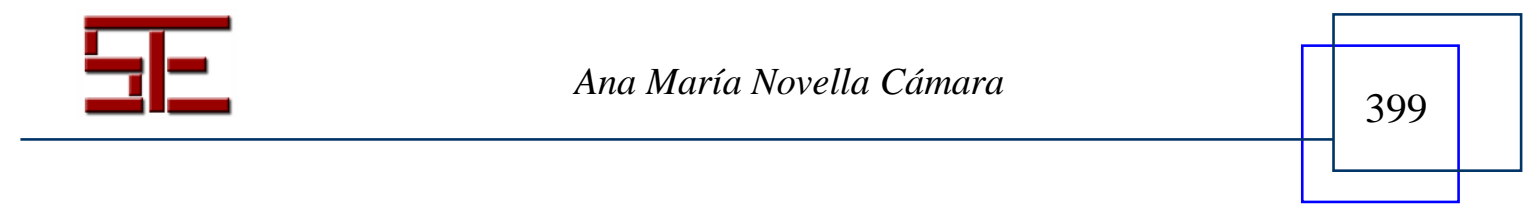



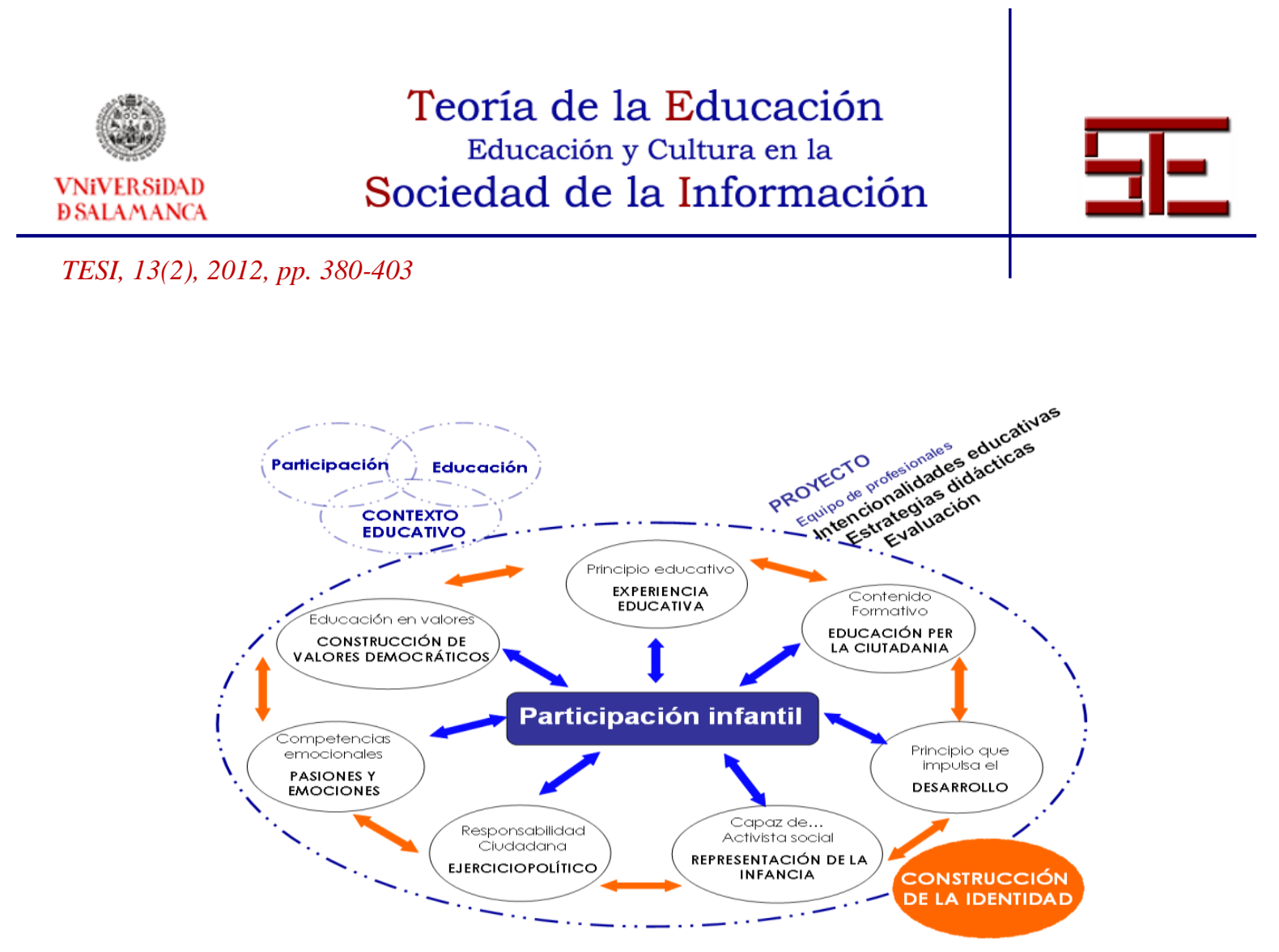

Gráfico 2. La participación infantil, complejo dimensional en pro de la autonomía ciudadana

\section{4.- LA PARTICIPACIÓN INFANTIL EN PRO DE LA AUTONOMÍA CIUDADANA}

Los niños y las niñas son ciudadanos comprometidos en aquellos proyectos de los que forman parte. Puig (2005) define un ciudadano activo como aquella persona que sabe exigir sus derechos, cumplir sus deberes para con la comunidad y contribuir al bien común. Los niños y las niñas que participan activamente en su ciudad son capaces de cumplir estos tres requisitos. A medida que se implican en experiencias participativas, incorporan nuevos procedimientos, como el autoconocimiento, el conocimiento de los demás, la comprensión crítica, el juicio, las habilidades dialógicas, la toma de conciencia, la autorregulación... y la construcción de valores democráticos. La participación se convierte en un valor precioso que cultiva la autonomía y la autoestima porque se dan cuenta de que trabajar juntos e implicarse vale la pena, sirve para algo. Tienen muy claro que se reúnen para ver cómo ejercer su activismo ante las necesidades de su ciudad y ven cómo su trabajo se concreta en pequeñas mejoras de su realidad inmediata.

Para promover la participación de la infancia, es necesario definir prácticas educativas organizadas y ritualizadas, para que los niños intervengan como activistas de los procesos participativos cada vez más complejos donde desarrollaran su autonomía ciudadana cada vez más responsable y comprometida. Estas prácticas que forman "en",

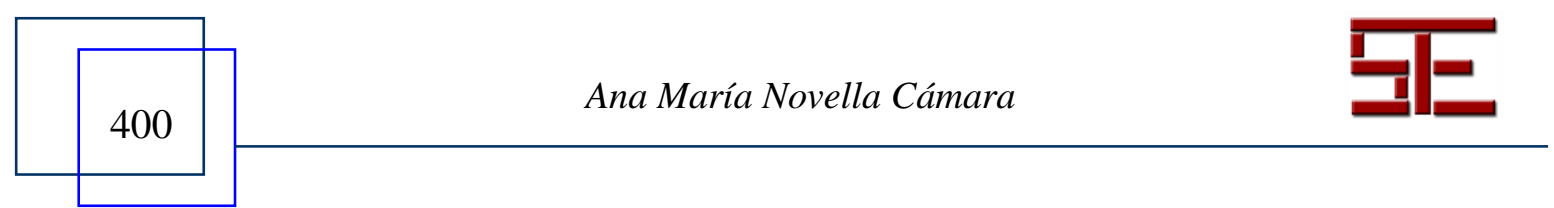




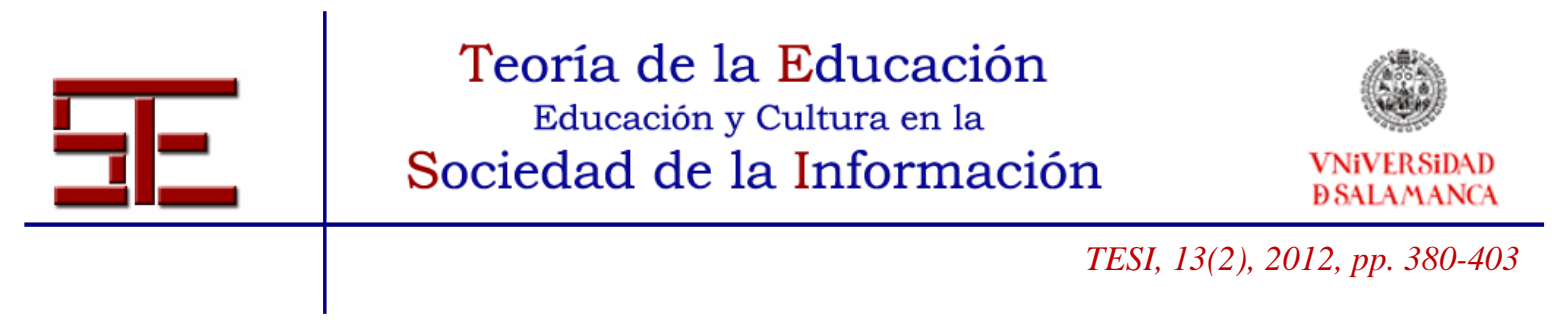

"para a" y "desde" la participación implican un combinado de estrategias socioafectivas, de deliberación y de actuación.

A continuación, destacamos algunas orientaciones para garantizar la participación en pro de la autonomía ciudadana:

- Incorporar a los niños en los espacios de diseño, definición, planificación, ejecución y evaluación desde las acciones más pequeñas a los proyectos más grandes.

- La participación de los niños, para que tenga sentido y sea eficaz en el ámbito de las relaciones comunidad, hace falta que sea vehicular.

- La participación infantil se debe dar en el entorno más próximo, a partir de realidades que están al alcance y no son simples abstracciones.

- La participación se concreta y se ritualiza, ha de invadir la complejidad de las relaciones educativas desde las intenciones a las metodologías sin descuidar los espacios de decisión.

- Ha de implicar transformaciones que se perciban y trasciendan. Los niños deben ver que su participación vale la pena, transforma su cotidianidad y es reconocida por sus conciudadanos.

- El protagonismo del niño mediante la participación supone un grado de compromiso de empoderamiento, de dotar de competencias para su ejercicio y de ir desarrollándolas para llegar a una mayor autonomía comprometida en el yo, con el nosotros, con el ellos y el TODOS.

Los niños que están inmersos en prácticas participativas se sienten reconocidos y desde aquí construyen su identidad, que ha de estar construida "desde" y "para" la autonomía. En definitiva, los grandes retos de la participación infantil son que se diseñen prácticas que articulen las múltiples dimensiones del concepto para que éstas sean experiencias personales y colectivas que transciendan en la formación de la ciudadanía y la capacidad de los niños y niñas de ejercer su autonomía ciudadana.

\section{5.- REFERENCIAS BIBLIOGRÁFICAS}

Alfageme, E., Cantos, R. y Martínez, M. (2003). De la participación al protagonismo infantil. Propuestas para la acción. Madrid: Plataforma de Organizaciones de Infancia.

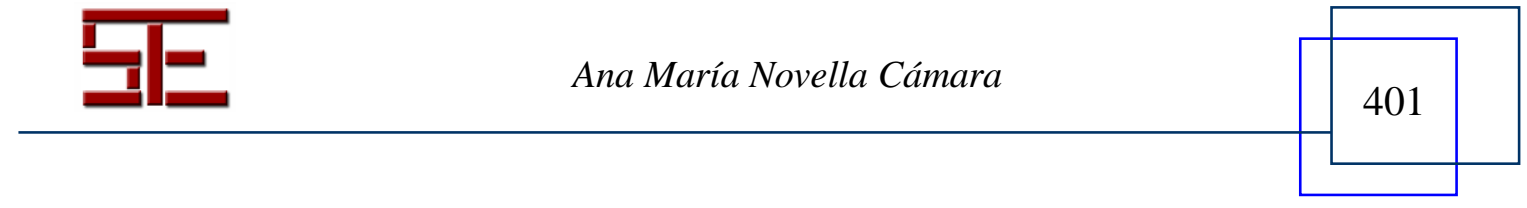




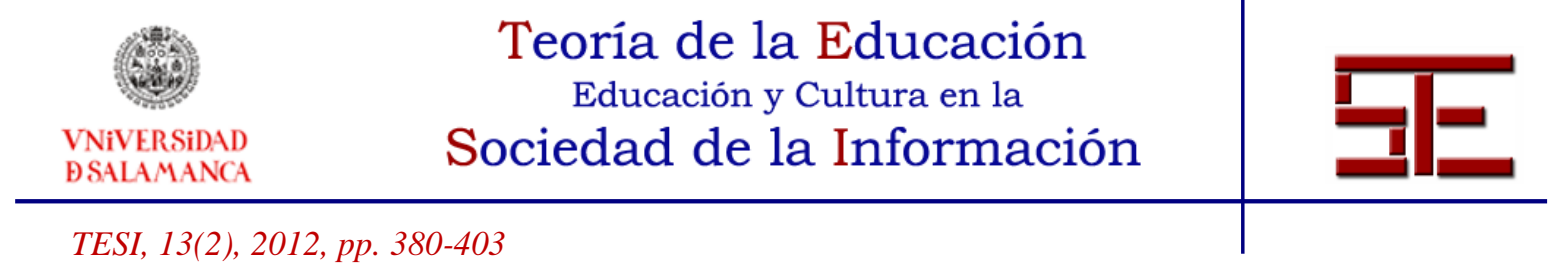

Araujo, J. (1999). Educación y ciudad sostenible. En F. Vallbé, J. Colomer y I. Compte (Coords.). Educació i canvi social. Cicle de conferències realitzades en el marc del Projecte Educatiu de Sabadell. Ajuntament de Sabadell.

Casas, F. (1995). La participación de los niños y niñas en la sociedad europea. Infancia y Sociedad, 31-32, 37-49.

- (1998). Infancia: Perspectivas psicosociales. Barcelona: Paidós.

Casas, F., González, M., Carme, M., Navarro, D., Malo, S., Figuer, C. y Bertran I. (2008). Informe sobre experiencias de participación social efectiva de niños, niñas y adolescentes [Versión electrónica]. Madrid: Ministerio de Educación, Política Social y Deporte.

Castells, M. (1986). La Ciudad y las masas: sociología de los movimientos sociales urbanos. Madrid: Alianza (versión española de Rosendo Gallego).

Cortina, A. (1997). Ciudadanos del mundo. Hacia una teoría de la ciudadanía. Madrid: Alianza Editorial.

- (1999). Los ciudadanos como protagonistas. Barcelona: Galaxia Gutenberg.

Cussianovich, A., Alfageme, E., Arenas, F., Castro, J. y Oviedo, J. R. (2001). La infancia en los escenarios futuros. Lima: Edit. Universidad Nacional Mayor San Marcos.

Fernández Enguita, M. (1992). Poder y participación en el sistema educativo. Sobre las contradicciones de la organización escolar en un contexto democrático. Barcelona: Paidós.

García, G. y Micco, S. (1997). Hacia una teoría del preciudadano. En C. Pizarro y E. Palma (Eds.), Niñez y democracia. Colombia: Ariel/Unicef.

Gaytán, A. (1998). Protagonismo infantil. Un proceso social de organización, participación y expresión de niñas, niños y adolescentes. Guatemala: Redd Barna.

Novella, A. (2008). Los consejos infantiles: oportunidades y retos de la participación infantil en la ciudad. En E. Soriano (Comps.), Educar para la ciudadanía intercultural y democratica (pp. 227-256). Madrid: Muralla.

- (2009). La participació dels infants a la ciutat des del Consell d'Infants. Barcelona: Departament d'Acció Social i Ciutadania. Generalitat de Catalunya. Extraído el 6 Julio, 2012, de

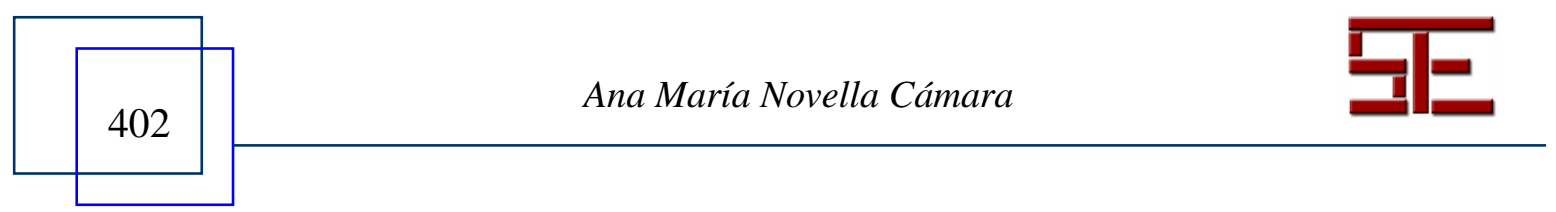




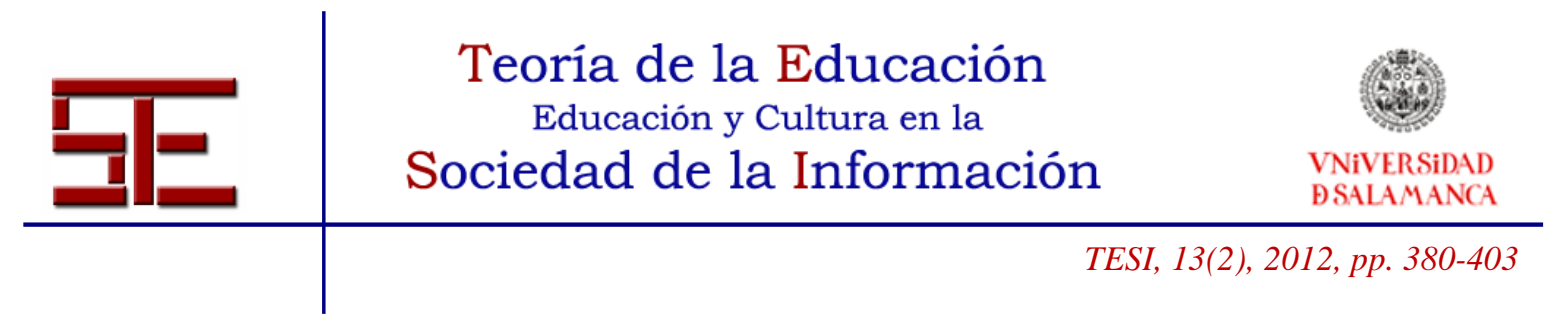

http://www20.gencat/docs/dasc/01Departament/08Publicacions/Infancia_i_ adolescencia/Num_2/Participacio\%02infants\%20ciutat.pdf

Puig, J. M. (1996). La construcció de la personalitat moral. Barcelona: Paidós.

- (2001). Alexandrer S. Neill y las pedagogías antiautoritarias. En J. Trilla (Coord.) El legado pedagógico del siglo XX para la escuela del siglo XXI (pp. 151-176). Barcelona: Graó.

- (2005). Lo necesitamos todo. El País, 11 de diciembre de 2005.

Rogoff, B. (1997). Los tres planos de la actividad sociocultural: apropiación participativa, participación guiada y aprendizaje. En J. M. Wertsch, P. del Río y A. Álvarez (Comps.). La mente sociocultural. Aproximaciones teóricas y aplicadas (pp. 111-128). Madrid: Fundación Infancia y Aprendizaje.

Shier, H. (2009). Children as Public Actors: Navigating the Tensions. Children and Society, 24, 24-37.

Subirats, J. (2004). ¿Qué educación para que ciudades? Ponencia presentada en el VIII Congrés Ciutats Educadores. Génova.

Trilla, J. (1998). Pensar la ciutat des de l'educació. Document del seminari Projecte educatiu de ciutat. Temes d'Educació, 12, 13-55.

Trilla, J. (2000). Pedagogia del grup i del projecte. Una aproximació a l'obra de Joaquim Franch. Barcelona: Edicions 62-Rosa Sensat.

Trilla, J. y Novella, A. M (2011). Participación y formación para la ciudadanía. Los consejos infantiles [Versión electrónica]. Revista de Educación, 356, 23-43.

Para citar el presente artículo puede utilizar la siguiente referencia:

Novella Cámara, A. M. (2012). La participación infantil: concepto dimensional en pro de la autonomía ciudadana. Revista Teoría de la Educación: Educación y Cultura en la Sociedad de la Información. 13(2), 380-403 [Fecha de consulta: dd/mm/aaaa].

http://campus.usal.es/ revistas_trabajo/index.php/revistatesi/article/view/9015/9259

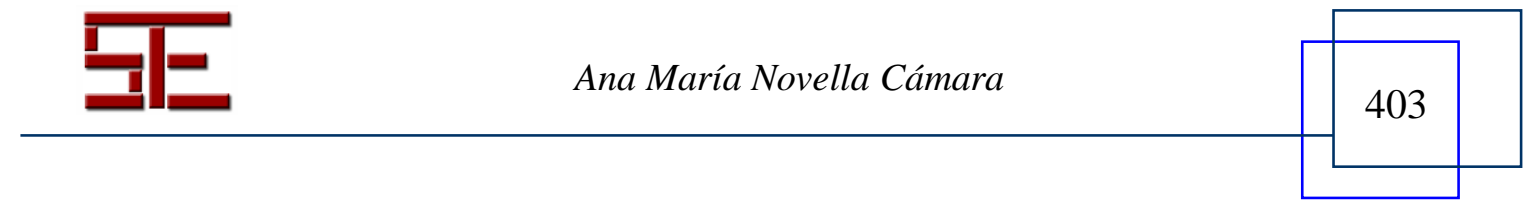

